\title{
SMART(PHONE) INVESTING? A WITHIN INVESTOR-TIME ANALYSIS OF NEW TECHNOLOGIES AND TRADING BEHAVIOR.
}

\author{
Ankit Kalda \\ Benjamin Loos \\ Alessandro Previtero \\ Andreas Hackethal \\ Working Paper 28363 \\ http://www.nber.org/papers/w28363
NATIONAL BUREAU OF ECONOMIC RESEARCH
1050 Massachusetts Avenue
Cambridge, MA 02138
January 2021

We thank Shlomo Benartzi, Juhani Linnainmaa, Ulrike Malmendier, Brian Melzer, and seminar participants at Indiana University and BI Norwegian Business School for helpful comments and discussions. The views expressed herein are those of the authors and do not necessarily reflect the views of the National Bureau of Economic Research.

NBER working papers are circulated for discussion and comment purposes. They have not been peer-reviewed or been subject to the review by the NBER Board of Directors that accompanies official NBER publications.

(C) 2021 by Ankit Kalda, Benjamin Loos, Alessandro Previtero, and Andreas Hackethal. All rights reserved. Short sections of text, not to exceed two paragraphs, may be quoted without explicit permission provided that full credit, including $\odot$ notice, is given to the source. 
Smart(Phone) Investing? A within Investor-time Analysis of New Technologies and Trading Behavior.

Ankit Kalda, Benjamin Loos, Alessandro Previtero, and Andreas Hackethal

NBER Working Paper No. 28363

January 2021

JEL No. G11,G40,G50

\section{ABSTRACT}

Using transaction-level data from two German banks, we study the effects of smartphones on investor behavior. Comparing trades by the same investor in the same month across different platforms, we find that smartphones increase purchasing of riskier and lottery-type assets and chasing past returns. After the adoption of smartphones, investors do not substitute trades across platforms and buy also riskier, lottery-type, and hot investments on other platforms. Using smartphones to trade specific assets or during specific hours contributes to explain our results. Digital nudges and the device screen size do not mechanically drive our results. Smartphone effects are not transitory.

Ankit Kalda

Kelley School of Business

1309 E 10th St

Indiana University

Bloomington, IN 47405

akalda@iu.edu

Benjamin Loos

TUM School of Management

Arcissstrasse 21

Munich 80333

Germany

beni.loos@gmail.com

\author{
Alessandro Previtero \\ Kelley School of Business \\ Indiana University \\ 1309 E. 10th Street \\ Bloomington, IN 47405 \\ and NBER \\ aleprevi@indiana.edu \\ Andreas Hackethal \\ Goethe University Frankfurt \\ Grüneburgplatz 1 House of Finance \\ 60323 Frankfurt a.M. Germany \\ hackethal@gbs.uni-frankfurt.de
}




\section{Introduction}

Technology has dramatically changed how retail investors trade, from placing orders using direct dial-up connections in the 1980s or Internet-based trading in the 1990s to the more recent rise of robo-advisers. With few exceptions, the introduction of these new technologies is generally associated with a decline in investor portfolio efficiency. ${ }^{1}$ Whether good or bad for investors, it is accepted that new technologies influence investor behavior. The empirical evidence in these studies comes from some comparisons of investor behavior before and after the adoption of the new technology, potentially contrasted with the behavior over time of another group that did not adopt the technology. Under the assumption that, absent the innovation, investors would have behaved in the exact same way, a common interpretation of this evidence is that new technologies influence investors and change their behavior. An alternative explanation is that investors, instead, adopt the new technology because they are willing to change their trading behavior in the first place. Even if we could randomly assign the new technology to investors, ${ }^{2}$ it would still not be straightforward to conclude that the new technology changes the overall investor portfolio. If investors manage investments across different accounts or platforms, they could decide to substitute across technologies. Therefore, observing trades on one platform might not be informative of the overall investor trading behavior.

While previous studies lack the data to distinguish between these alternative interpretations, their implications are, however, starkly different. If the new technology influences investor preferences and beliefs, absent the technology investors would have not changed their trading behavior. If, instead, it fulfills untapped investor demand, then the new tech-

\footnotetext{
${ }^{1}$ For example, when moving to online trading, investors increased turnover and reduced performance (Barber and Odean, 2002). More recent studies document, instead, that robo-advisers could reduce investment mistakes (see D'Acunto, Prabhala and Rossi, 2019; Loos et al., 2020).

${ }^{2}$ D'Acunto, Prabhala and Rossi (2019) use the randomness in investors answering their phone to the marketing enrollment calls as a plausibly exogenous shock to the probability of joining the robo-advisor.
} 
nology at best accelerates or makes less costly a change in investor behavior that would have happened anyway. Analogously, the new technology could just fulfill substitute demand, if investors substitute trades across different platforms. Therefore, simple comparisons of investor behavior pre- and post-adoption or analyses of trades on one single platform could vastly overestimate the effects of the new technology. Furthermore, the policy implications could not be any more different. Is the technology helping investors to achieve their goals by facilitating their trades? Or is technology influencing adopters in profound ways that could stray investors away from their original goals? ${ }^{3}$

In this paper, we use unique data on German households to overcome these empirical challenges and to weigh in on the question if technology drives changes or just fulfills untapped or substitute investor demand. Our data comes from two large German retail banks that have introduced trading applications for mobile devices. For over 15,000 bank clients that have used these mobile apps in the years 2010-2017, we can observe all holdings and transactions, and, more important, the specific platform used for each trade (e.g., personal computer vs. smartphone). These unique features of the data prove fruitful for our analyses. That is, we can conduct all our main tests comparing trades done by the same investor in the same month across different platforms. Moreover, we can directly test for substitution effects.

We present four set of results. First, we study if the use of smartphones induces differences in the riskiness of trades. Comparing trades by the same investor in the same year-month, we find that the probability of purchasing risky assets increases in smartphone trades compared to non-smartphone ones. Analogously, smartphone trades involve assets with higher volatility and more positive skewness. This evidence is best summarized by our analyses of lottery type stocks. ${ }^{4}$ Smartphones increase the probability

\footnotetext{
${ }^{3}$ In a 2020 article titled "Robinhood Has Lured Young Traders, Sometimes With Devastating Results", the New York Times features a series of stories of investors that have lost substantial amount of money trading off their mobile phones.

${ }^{4}$ Following Kumar (2009), we define as lottery-type stocks those assets with below median prices and
} 
of buying lottery-type stocks by $67 \%$ of the unconditional mean for smartphone users.

Second, we examine the effects of smartphones on the tendency to chase past returns. We find that smartphones increase the probability of buying assets in the top decile of the past performance distribution. Smartphones increase the probability of buying assets in the top 10 percent of past performance by 12.0 percentage points (or $70.6 \%$ of the unconditional mean).

Third, we investigate if investors selectively use smartphone to execute their risky, lottery-type, and trend-chasing trades. In this scenario, investors could simply substitute their trades from one device to another, without any real consequences for their overall portfolio efficiency. Using a difference-in-differences design that compares iOS and Android users, we find that, following the launch of smartphone apps, investors are-if anything-more likely to purchase risky and lottery-type assets and to chase hot investments also on non-smartphone platforms. While inconsistent with substitution effects, this evidence potentially suggests that investors are learning to become overall more biased after their initial use of smartphones to trade.

Last, we evaluate the mechanisms that may drive these smartphone effects. We begin by examining whether the ability to trade anytime and everywhere via smartphones drives our results. To evaluate the importance of this channel, we repeat our analyses, including year-by-time-of-the-day fixed effects. In this specification, our estimates become smaller but remain economically and statistically significant. This finding suggests that time of trade is important in our setting, but it does not fully explain our findings. Consistent with this interpretation, heterogeneity analyses show that smartphone effects are stronger during after-hours (i.e. following exchange closure). Institutional differences between trading on official exchanges and in after-hours markets do not drive this heterogeneity. Given that individuals are more likely to rely on the more intuitive system 1 later in the above median skewness and volatility. 
day (Kahneman,2011), stronger effects during after-hours are consistent with smartphones facilitating trades based more on system 1 thinking.

Alternatively, investors may use smartphones to trade different investments and this selection of riskier asset classes may drive our results. We re-estimate our main analyses, including year-by-asset-class fixed effects. We find again smaller but still strong smartphone effects, suggesting that the choice of asset classes doesn't fully explain our findings.

Another possibility is that digital nudges might contribute to our results. Smartphone trading apps in fact prominently feature stocks that have experienced dramatic positive (and negative) performance in the recent past. If these stocks are riskier and with higher skewness, digital nudges could mechanically influence investor behavior. To test for this hypothesis, we re-run our main specifications separately for different asset classes: individual stocks, mutual funds, and other investments (options, certificates, and warrants). We find that our results are strong across all asset classes and not just for individual stocks that can be more prominently featured in the smartphone trading app. Additionally, we test if a physical attribute of smartphones-their smaller screen-contributes to our findings. To explore this mechanism, we separately investigate the effects of trading via devices with different screen sizes (iPhones vs. iPads). Given that we do not find stronger results for trades via iPhones, we conclude that this physical attribute is not likely to drive our findings. Last, our results do not appear to be short-lived and driven by the initial enthusiasm or the learning curve of the new technology. Our estimates do not change significantly between the first quarter up to the tenth quarter after the initial use of the smartphone app.

Our findings contribute to literature on the effects of technology on investor behavior. Barber and Odean (2002) document that investors who switched from phone-based to online trading start trading more frequently, but less profitably than before. Choi, Laibson, 
and Metrick (2002) document similar results in 401(k) plans. Our evidence complements these studies by documenting that smartphones increase the purchases of lottery-type stock and trend-chasing. More importantly, we document different behaviors within the same investor and same month, but across platforms. This identification strategy enables us to more convincingly address selection effects when examining how a new technology impacts investor behavior.

Given the large diffusion of robo-advisers in the past decade, D'Acunto, Prabhala and Rossi (2019) and Loos et al. (2020) have investigated the effects of this innovation on investor behavior. Both studies highlight that robo-advice has the potential to reduce investment biases and improve portfolio performance. Our evidence provide a more nuanced picture of the effects of new technologies on investor behavior. Smartphones appear to foster investment biases such as investing in lottery-type and hot stocks. Our paper contributes also to the recent literature on the effect of mobile apps on financial behaviors. Levi and Benartzi (2020) and D'Acunto, Rossi, and Weber (2020) study the effects of mobile applications on spending behaviors. We contribute to these studies by investigating investment decisions. Our setting provides a nice laboratory to understand the consequences of providing constant feedback and ease of execution of trades to retail investors.

More recently, a series of studies have investigated the effects of trading smartphone apps on aggregate markets. Using data from the US retail brokerage company Robin Hood, Welch (2020) finds that a portfolio mimicking the aggregate holdings of Robin Hood investors did not underperform standard academic benchmarks. ${ }^{5}$ Using the same data, Barber et al. (2020) document that episodes of intense buying activity by Robinhood users are followed by negative returns. Using data from a leading investment adviser in China,

${ }^{5}$ Robin Hood operates entirely online via a website and mobile apps. The vast majority of its trades are made using the smartphone apps. 
Cen (2019) shows that, after the mobile app introduction, investors flows into mutual funds become more volatile and more sensitive to short-term fund returns and market sentiment. Our results nicely dovetail with the findings in these studies and make three distinctive contributions. First, we focus on the consequences of smartphones on retail investors, and not aggregate markets. Aggregate effects might mask substantial investor heterogeneity, making it difficult to understand potential redistributive effects of this technology. Second, our investor trading data allow to sharpen the causal interpretation of smartphone effects and to investigate the mechanisms driving them. Third, while Robinhood investors are Millennials with little or no trading experience, the German investors that adopt smartphone trading are, on average, 45 years old with nine years of experience investing with the banks. Therefore, we can capture the effects of smartphone trading on more experienced users and a more representative sample of traders.

\section{Hypotheses Development}

New technologies can change the way households make economic decisions, from labor supply, to borrowing, to investor behavior. ${ }^{6}$ Broadly speaking, we investigate if smartphones influence financial risk-taking and investment biases. The effects of smartphones in both settings are not obvious ex-ante. By facilitating searching and monitoring efforts, smartphones can reduce the participation costs in the stock market and promote financial risk-taking. If investors are, instead, sensitive to short-term losses, the more frequent feedback via smartphones could reduce risk-taking, as predicted in the framework of myopic loss aversion by Benartzi and Thaler (1995). Consistent with myopic loss aversion, Haigh and List (2005) document that professional option traders take less risk

\footnotetext{
${ }^{6}$ For example, Fos et al (2019), Jackson (2019) and Koustas (2018) document the effect of ride-sharing apps on labor market decisions; Di Maggio and Yao (2019), Buchak, Matvos, Piskorski and Seru (2018) and Fuster et al. (2018) document the effect of Fintech lending on borrowing decisions; and D'Acunto, Prahabala, and Rossi (2019) document the effect of robo-advising on investment decisions.
} 
when randomly assigned to the treatment of receiving more frequent feedback.

Psychologists hypothesize that we have two modes of thinking: system 1, which is fast, instinctive and emotional, and system 2, which is slower, more deliberative, and more logical (Stanovich and West, 2000; Kahneman, 2003). By providing the ability to almost instantaneously trade in more relaxed environments, smartphones may potentially allow more impulsive, system 1 trades. System 1 reasoning is associated with preference for lotteries (see Kahneman, 2011). Kumar (2009) documents that preference for gambling are correlated with lottery-type stocks with positively skewed payoffs. Moreover, Bali et al. (2019) find that investor preferences for lottery stocks are amplified by attention and social interaction. Collectively, this evidence suggests that smartphones might have a strong effects on preferences for lottery-type investments with positive skewness.

New technologies have the potential to reduce investment biases. While human advisors might make the same investment mistakes of their clients (Linnainmaa, Melzer, and Previtero, 2020), robo-advisers are a potential cost-effective solution that could increase portfolio efficiency (e.g., D'Acunto, Prahabala, and Rossi, 2019; Loos et al., 2020). Smartphones could grant ubiquitous access to information and high speed of execution of trades. Gargano and Rossi (2018) document the more attention to investment lead to higher profits. On the other hand, as previously discussed smartphones could promote more intuitive/ system 1 thinking and, possibly, higher reliance on value-destroying investment heuristics. For example, consumers are more inclined to make impulsive purchases such as ordering more unhealthy food when using mobile devices. Benartzi and Lehrer (2015) review of the effects of smartphones on consumer choices.

Given that their effects are ambiguous, we test if smartphones influence financial risktaking, preferences for lottery stocks, and the well-documented investment bias to chase past returns. 


\section{Data \& Empirics}

This section describes the data used in the analyses, discusses our sample and details our empirical strategy.

\subsection{Data \& Summary Statistics}

We use comprehensive investor transaction-level data from two large German retail banks. For a large random sample of clients at the banks, we observe the securities traded, the type of trade (buys vs. sell), day and time of the trade execution, price and units of each transaction, and, more important for our analysis, the platform used for each trade. The customers in our data hold their primary accounts with these two banks and use them for most of their transactions. This data covers about sixty five million transactions over the years from 1999 to 2017 by over two hundred and twenty five thousand investors. The data from first bank covers information on over forty five million transactions by one hundred and ten thousand investors from 1999 to 2016 . The data from the second bank covers close to twenty million transactions by one hundred and sixteen thousand investors from 2003 to 2017. At the investor level, we observe monthly snapshots of portfolio holdings and demographic characteristics such as gender, age, wealth, and income. ${ }^{7}$

Most of our analyses uses transaction data where we impose three sample filters. First, we limit our sample between 2010 and 2016 for one bank and from 2013 to 2017 for the other bank. We choose these years to reflect the earliest smartphone apps introduction for each bank. 8 Second, we drop trades associated with savings plans and wealth management services because these are automated or don't involve an active choice from investors. Finally, we drop trades without information on the asset traded (e.g., asset class). Applying these filters results in a sample of over twenty two million transactions

\footnotetext{
${ }^{7}$ Wealth and income are only recorded at the account opening.

${ }^{8}$ Our results are robust if we separately estimate them for each bank
} 
by roughly one hundred and eighty thousand investors. Over eighteen thousand of these investors use smartphone trading apps at least once.

We complement the proprietary data from the two banks with publicly available data on prices, returns, and other characteristics for all securities traded within Germany. Table 1 reports summary statistics for variables used in our analyses within our sample. Smartphone is a dummy variable that takes a value of one for trades executed using smartphones. On average, $2 \%$ of trades in our sample are placed using smartphones (standard deviation of 0.15). However, conditional on ever using them, investors execute over $15 \%$ of their trades via smartphones. We first measure risk taking as the probability of purchasing risky assets (i.e., direct and indirect equity holdings). The average probability of purchasing risky assets in our sample is $93 \%$.We also measure risk taking as the volatility of the assets purchased, measured as the annualized standard deviation over a trailing 12-month rolling window. The mean volatility in our sample is $17.27 \%$ with a standard deviation of $13.14 \%$.

Our measures for gambling preferences include investment skewness, calculated on a 12-month rolling window, and the probability of purchasing lottery type assets. Following Kumar (2009), we define lottery-type assets as those with below median price, and above median volatility and skewness. The mean probability of purchasing a lottery-type asset within our sample is $7 \%$. To examine trend chasing, we use the probability of purchasing assets in the top decile of the past return distribution (we use a trailing 12-month window). Finally, we use the bank-reported risk categories of the assets purchased and the probability of purchasing warrants or certificates. The banks' risk-categories apply to all the assets traded by the clients and range between one and five, with higher values representing greater risks. The average risk category for the assets purchased in our sample is 3.99. The mean probability of purchasing a warrant is $9 \%$ (3\% for a certificate).

In Figure 1, we explore the evolution of the usage of smartphones over our sample 
period. Panel A plots the percentage of trades that occur via smartphones on the Y-axis against calendar year on the X-axis. One of the two banks in our sample launched a smartphone trading app in 2010. By 2017, the end of our sample, over $2.5 \%$ of all trades were occurring over smartphones. The average usage drops in 2013 because we add to our data a second bank which launched its own trading app in 2013. Among investors with the bank that first introduced the trading app, $4 \%$ of all trades were via smartphones in 2017. Although the overall fraction of total trades might appear small, the adoption rates are steadily increasing with over 10\% of all investors using smartphone trading by 2017 . Panel B plots the percentage of trades that occur via smartphones only for those investors who have used the smartphone app at least once. Among these investors, the fraction of smartphone trades is much higher, reaching over $20 \%$ of all their trades by 2017 . Thus, if smartphone trades differ from other trades, they might have a significant impact on the overall portfolio efficiency.

Since investors endogenously choose to use smartphones, adopters might be inherently different from non-adopters. In Table 2, we compare trading behavior (Panel A) and investor characteristics (Panel B) across smartphone users and non-users. For non-users, we compute summary statistics over all the years in our sample. For smartphone users, instead, we use only information until their first smartphone trade. Therefore, trading statistics for adopters do not reflect the effects of smartphones. Compare to non-users, adopters trade more frequently (10 vs. five trades per month) and place larger trades $(4,477$ vs. 3,813 euros in average trades). Smartphone users are also more likely to buy riskier assets (95\% vs. $92 \%$ ) and purchase more volatile assets (22\% volatility vs. $16.52 \%)$. Finally, adopters display a higher probability of buying lottery-type assets and investments in the top decile of the past return distribution.

Panel B reports investor-level characteristics for smartphone users and non-users. While there are no differences in terms of income and wealth, adopters tend to be younger 
males with shorter tenure at the bank. 9 Specifically, smartphone users have one year shorter tenure at the bank, are about 8 years younger, and 13\% more likely to be males compared to non-users.

\subsection{Empirical Challenges and Methodology}

Investigating the effects of new technologies on trading activity poses significant empirical challenges, because of selection and substitution effects. Individuals who use smartphones to trade could be different from investors that use other platforms. In our sample, smartphone users are more active, more likely to buy higher volatility and lotterytype assets, and to chase past top performers. These differences highlight the importance of conducting within-investor analyses. While a within-investor analysis could address this type of selection, investor characteristics could also change over time. For instance, individuals can become more sophisticated or start trading more actively over time. These changes might drive their choice of the trading platform. Therefore, the selection effects could operate at the investor-time level.

Thanks to the richness of our data, we are able to go one step further in addressing this concern. We exploit within individual-by-time variation, by including in our estimations individual-by-month (or by-year) fixed effects. By comparing trades across different platforms made by the same investor within the same month (or year), we can account for time-varying investor characteristics and selection at the investor-time level. Specifically, we estimate the following model:

$$
y_{i, j, t}=\beta \times \text { Smartphone }_{i, j, t}+\delta_{i, t}\left(\delta_{i}\right)+\epsilon_{i, j, t}
$$

where $y$ measures behaviors (such as risk-taking, preference for lottery stocks and trend

\footnotetext{
${ }^{9}$ Income and wealth bins are measured at the time investors begin their relationship with the bank.
} 
chasing) by investor $i$ using platform $j$ during year-month $t$. Smartphone $e_{i, j, t}$ is an indicator variable equal to one for investor $i$ for smartphone trades in month $t . \delta_{i, t}$ are investorby-month (year) fixed effects that account for time-varying unobserved differences at the investor level. To evaluate the importance of across- and within- investor heterogeneity in our setting, we also estimate the model without any fixed effects and with the inclusion of investor fixed effects $\left(\delta_{i}\right)$ for all our main results. Robust standard errors are doubleclustered at the investor and year-month level.

For estimating these regressions, we collapse our sample to the investor by month by trading platform level. For this purpose, we categorize the trading platforms in two groups: smartphones vs. all other devices. After collapsing the data, the unit of analysis in our regressions is the mean value of all trades by the same investor in the same month, using the same trading platform. This estimation strategy allows us to control for both across- and within- investor heterogeneity that may bias estimates (by having investorby-time f.e.), while allowing trades within the same investor and the same month to be correlated (by double clustering the standard errors).

There is a potential trade-off when using investor-by-time fixed effects. We gain benefits in term of identification at the expenses of external validity of our results. With these fixed effects we can achieve better identification by accounting for time-varying unobserved differences at the investor level. Nonetheless, our results come only from those investors that trade using both platforms within the same year or month. These investors might or might not be a representative sample of all the smartphone traders. To be transparent about this trade-off, we run all our major analyses using different specifications. First, we report results without any fixed effect. Then, we include investor and time fixed effects. Last, we introduce results with investor-by-year and investors-by-month fixed effects. As we introduce more and more restrictive specifications, we move towards better identification but possibly away from more external validity. 
Another concern when estimating the effects of new technologies is that investors could use the new platform to execute specific types of trades (e.g., buying riskier investments), substituting away from other platforms. In the presence of substitution effects, we might mistakenly attribute variation in trading strategies to the use of smartphones, when indeed investors are just reallocating their trades across platforms. To test for this possibility, we conduct a difference-in-differences analysis, exploiting the staggered introduction of mobile apps across different operating systems (iOS vs. Android). By comparing nonsmartphone trades for smartphone users before and after the launch of different trading apps, we can establish how prevalent spillover and substitution effects are. Section 5 discusses this analysis and its results in detail.

\section{Main Results}

We examine the association between the use of smartphones and three trading behaviors: risk-taking, preferences for lottery-type assets, and trend chasing. As discussed in Section 2, the effects of smartphones on these behaviors are not obvious ex-ante. By facilitating more timely information acquisition, smartphones can reduce participation costs and, therefore, increase financial risk-taking. Analogously, by reducing monitoring costs, smartphones can promote more efficient trades and potentially reduce investment biases. Smartphones, however, provide also ubiquitous access and high speed of execution of trades. This constant feedback might discourage risk-taking, if investors are very sensitive to their losses (as in the myopic loss-aversion framework by Benartzi and Thaler, 1995). Additionally, access anywhere and anytime might foster more system 1 thinking (Kahneman,2011). System 1 has long been associated with more intuitive and impulsive actions, preferences for gambling and, consequently, lottery-type assets and could exacerbate biases, such as trend chasing. 


\subsection{Risk Taking}

We first analyze the effects of smartphones on financial risk-taking. In table 3, we report results for this analysis, estimating different versions of Equation 1. Our outcome is an indicator variable that captures the probability of purchasing risky assets. We define as risky assets direct and indirect stock holdings, that is stocks and equity mutual funds. Bonds, bond funds or gold-related funds are treated as non-equity investments. ${ }^{10}$ In Column (1) we do not include fixed effects. In this specification we find that the probability of purchasing risky assets is five percentage points (pp) higher for trades done using smartphones relative to other trades. This effect corresponds to an increase of $5.2 \%$ of the unconditional sample mean for smartphone users (0.95). While we find a significant effect of smartphones, unobservable (to us) heterogeneity between smartphone users and non-users can drive this result. In Column (2), we control for time-invariant investor heterogeneity by including investor fixed effects. We also account for nation-wide time trends by including year fixed effects. Consistent with these factors playing a role, our estimates are smaller- $2.11 \%$ of the sample mean-but still statistically significant at $1 \%$ level.

Our estimates in Column (2) could also be biased because of omitted time-varying investor characteristics. For example, investor risk preferences could vary over time and this variation could be correlated with the decision to adopt smartphone trading. We control for this possibility in Column (3) by including investor-by-year fixed effects in our estimation. This specification compares trades done by the same investor within the same year, using smartphones versus other platforms. Using this specification, we find that investors are three pp more likely to purchase a risky asset when trading using smartphones. Finally, in Column (4) we use our most stringent specification by including

\footnotetext{
${ }^{10}$ In this analysis, we omit trades in other assets such as certificates and warrants that cannot be easily classified.
} 
investor-by-month fixed effects and comparing trades done by the same investor within the same year-month. Following the discussion in subsection 3.2, we recall that while this more stringent specification allows for better identification, these results are based solely on those investors that execute multiple trades across different platforms during the same month. Using this specification, we find that the probability of purchasing a risky asset increases by four $\mathrm{pp}-4.3 \%$ of the sample mean — when using the smartphone versus other platforms.

Since the unconditional mean of purchasing risky assets for smartphone users is high (0.95), the effects previously estimated might not fully capture the increased risk taking induced by smartphone use. Therefore, we use the volatility of the assets purchased as a second complementary measure of risk-taking. We measure this volatility as the annualized standard deviation of returns over the past 12 months. We report the volatility results in Table 4. Using a specification without any fixed effects (Column 1), we find that the volatility of assets purchased using smartphones is 12.07pp higher compared to the volatility of other assets. This magnitude is economically large as it corresponds to $54.8 \%$ of the sample mean. However, both across- and within- investor heterogeneity might drive this estimate. When we control for both investor and year fixed effects in Column (2), we estimate a smaller effect for smartphones, equal to 4.43pp. In our most stringent specification in Column (4), we find that volatility of assets purchased using smartphones is 9.28pp higher than the volatility of other assets purchased by the same investor within

the same year-month. This magnitude is economically large as it corresponds to $42.2 \%$ of the unconditional mean.

\subsection{Preferences for lottery-type stocks}

We start the investigation of preferences for lottery-type assets by studying the skewness of the assets purchased. Retail investors generally prefer positively skewed assets 
(e.g., Kumar, 2009). We present these results in table 5. In Column (1), we find that smartphone use increases the skewness of investments by 19.23pp or $33.4 \%$ of the standard deviation of the skewness for phone users (57.58). As in previous tables, this first column does not include any fixed effects. When we add fixed effects, we estimate smaller, but still economically and statistically significant results, consistently with previous results. For example, in Column (4) we find that after controlling for investor-by-month fixed effects smartphone use increases skewness of asset purchased by 14.40 , or $25 \%$ of the standard deviation of the skewness for phone users.

In table 6, we measure more directly preferences for lottery-type assets. Following Kumar (2009), we define as lottery-type those assets that have in their asset classes below median prices, above median volatility, and above median skewness. In Column (1), we find that—without including any fixed effects—smartphone trades increase the probability of purchasing lottery-type assets by $10 \mathrm{pp}$, or $83 \%$ of the unconditional mean for smartphone users. We still find statistically and economically significant results, even after the inclusion of the same fixed effects previously used. Under the most restrictive specification with investor-by-month fixed effects, we find that smartphone trades increase the probability of purchasing lottery-type assets by $8 \mathrm{pp}$, or $67 \%$ of the unconditional mean.

\subsection{Trend Chasing}

Smartphones allow investors to access information on their investments on a more timely basis. We investigate if smartphone influence the tendency of investors to chase past returns and buy "hot" investments, or assets that have performed unusually well in the recent past. In our overall sample $68 \%$ of purchases involve assets that earned above median returns in the recent past. Even before adopting the smartphone app, users have $17 \%$ of their trades concentrated in the top 10 th percentile of past performers.

In table 7, we find that smartphone trades increase this tendency of buying assets in top 
10th percentile of past performance. Without fixed effects, in Column (1), we find that the probability of buying past winners goes up by $16.4 \mathrm{pp}$. After controlling for individual-bymonth fixed effects, we still find an economically and statistically significant result. Smart phone trades increase the likelihood of purchasing past winners by $12.0 \mathrm{pp}$ or $70.6 \%$ of the unconditional mean.

Overall, our results suggest that smartphones affect investor trades. Even comparing trades within the same investor-month, we still find that investors buy more volatile and higher skewness assets using smartphones. These tendencies result in a significant increase in the probability of purchasing lottery-type assets. Moreover, investors become significantly more likely to chase past returns.

\subsection{Do investors substitute their trades using smartphones?}

While our within investor-time analyses make progress in addressing potential selection problems, investors still endogenously decide which trading platform to use for each of their trades. They can predominantly execute on smartphones their high-volatility, high skewness, lottery-type of trades. In this case, smartphone trades are just substituting trades that would have occurred anyway in different platforms. In the presence of substitution effects, we should expect non-smartphone trades to display lower volatility, lower skewness, and to be less likely to involve lottery-type assets or past winners. Our data with information on both smartphone and non-smartphone trades allow us to directly test for substitution effects.

To identify these spill-over effects, we use a difference-in-differences approach that exploits the staggered adoption of the smartphone app by different clients of the two banks. This empirical approach allows us to compare different users before and after they start using the trading app. In practice, in this empirical design we compare early vs. late smartphone users. Empirically, we estimate the following equation: 


$$
y_{i, t}=\beta \times \text { SmartphoneUse }_{i, t}+\delta_{i}+\gamma_{t}+\epsilon_{i, j, t}
$$

where $y$ measures risk-taking, volatility, skewness, preferences for lottery-type assets and past winners for trades in non-smartphone platforms by investor $i$ during year-month t. SmartphoneUse $e_{i, t}$ is an indicator variable equal to one for investor $i$ in the months following the first trade using the smartphone app. $\delta_{i}$ represents investor fixed effects that control for non time-varying unobserved differences at the investor level. $\gamma_{t}$ represents year-month fixed effects.

We present these estimates in table 8 , panel $\mathrm{A}$. The coefficient of interest, $\beta$, is positive for all outcomes and statistically significant for four out of the five outcome variables (with the sole exception being the probability of buying risky assets). After using the smartphone app, investors start buying also on non-smartphone platforms assets with higher volatility and more positive skewness, and become more likely to purchase lotterytype assets and past winners. Although smaller in economic magnitude than our main effects, we find positive spillover effects on non-smartphone trades. This evidence goes against substitution effects and the hypothesis that investors largely select smartphones to execute their high volatility, high skewness trades. These results are consistent with investors learning from smartphone trading to other platforms.

A potential concern with this design is that investors endogenously choose to adopt the smartphone trading app. In other words, this analysis suffers from the potential selection effects between early and late users. To overcome this limitation, we run an additional difference-in-differences analysis that exploits the staggered launch of trading apps for different smartphone operating systems (iOS vs. Android). ${ }^{11}$ This empirical approach allows us to compare different users before and after the trading app for their smartphone

\footnotetext{
${ }^{11}$ This data is only available for one of the two banks in our sample. Hence, we limit this analysis to this one bank.
} 
operating system is launched. In practice, we estimate the following equation:

$$
y_{i, t}=\beta^{\prime} \times \text { SmartphoneLaunch } h_{i, t}+\delta_{i}^{\prime}+\gamma_{t}^{\prime}+\epsilon_{i, j, t}^{\prime}
$$

where $y$ measures our outcome of interest for trades in non-smartphone platforms by investor $i$ during year-month $t$. Smartphone aunch $_{i, t}$ is an indicator variable equal to one for investor $i$ in the months following the launch of the trading app for their smartphone operating system. $\delta_{i}^{\prime}$ represents investor fixed effects and $\gamma_{t}^{\prime}$ represents year-month fixed effects. We present these estimates in panel B of table 8. Consistent with the results in panel A, we also find positive spillover effects for all the outcome variables, with three out of five variables being statistically significant.

The identification assumption for this analysis is that of parallel trends, i.e. in the absence of the app launch, the trading behavior of investors owning different types of smartphones-iOS vs. Android devices-would have evolved in a parallel way. Although this assumption cannot be fully tested, we examine its validity in the pre-period by estimating the dynamics of smartphone effects over time. Figure 4 plots the coefficients of specifications in which the smartphone type is interacted with event-time in quarters. We plot estimates for the probability of purchasing risky asset (panel A), volatility (panel B), skewness (panel C), and trend-chasing (panel D). Across all outcomes, we find no statistically significant differences for investors owning different smartphones in the twoyear period before the app launch. After the launch, we do not detect negative effects, a finding that is inconsistent with substitution effect. If anything, we observe delayed positive spillover effects on non-smartphone trades. In this specification, the effects on non-smartphone trades are further delayed by the fact that not all the investors start using the app immediately after its launch. Moreover, if investors learn from smartphone trades, spillover effects could take time to manifest. Overall, this evidence is consistent with in- 
vestors learning from smartphone trades and adopting similar behaviors also when not trading using smartphones.

Overall, our results are inconsistent with substitution effect playing a role. If anything, our evidence suggest that there are positive spillover and that investors learn from their smartphone trading.

\section{Mechanism}

In this section we investigate what drives the differential trading behavior associated with smartphones. First, we test if using smartphones to trade at specific times of the day or to trade specific assets can explain our results. Then, we study if digital nudges or the device screen size generate our results. Last, we investigate if smartphone effects are short-lived or more permanent.

\subsection{Do investors use smartphones to trade during different hours?}

Smartphones potentially allow an immediate access to trading over an extended period of time. To evaluate if this extended access to trading drives our results, we first investigate trading dynamics over different hours of the day. In figure 2 panel A, we plot the density of trades per hour of the day for our entire sample, including both smartphone and nonsmartphone users. There are two peaks in trading activity. They coincide with the opening (9:00 to 10:00am) and the closing of the financial markets in Germany (4:00 to 5:00pm). In panel B we plot the same density separately for smartphone and non-smartphone users. The two density plots largely overlap, with smartphone users marginally more likely to trade around closing hours. In panel $\mathrm{C}$, we limit our analysis to smartphone users and plot separately their smartphone vs. non-smartphone trades. Again, there is no apparent difference in the two density plots. Traders use with similar frequency smartphones and 
other trading platforms during the day.

In table 9, we investigate more formally the effects of trading hours on our results, by including in our analyses both investor-by-month and trading hour-by-year fixed effects. This specification allows us to compare also trades made during the same hour of the day (e.g., 9:00am) in the same year. All our previous results are robust to this additional specification. Investors on smartphone are more likely to buy risky, lottery-type, and top-performing assets, and invest in more volatile and higher skewness assets. Compared to our previous results in tables 3 to 7 , the economic magnitudes are attenuated. They range from $35 \%$ of the previous estimate for the probability of purchasing risky assets (1.4pp vs. $4 \mathrm{pp})$ to $52.6 \%$ for the volatility of the assets purchased $(7.6 \%$ vs. 14.4$) \%)$. All the results remain economically significant. For example, the probability of buying lottery-type assets via smartphone increase by $3.2 \mathrm{pp}$, or $26.7 \%$ of the unconditional mean for smartphone users (12\%).

Although investors do not use smartphones more frequently than other platforms at specific hours of the day, the effects of smartphones on trading appear mitigated when we compare trades executed during similar hours (by including trading hour-by-year fixed effects). This evidence suggests that the effects of smartphones might vary across different hours of the day. We directly test this hypothesis by rerunning our main specifications separately for trades during market-hours (9am to $5 \mathrm{pm}$ ) vs. trades during after-hours (5pm to 10pm). We define the after-hour window based on the fact that local German market makers allow investors to trade between $5 \mathrm{pm}$ and $10 \mathrm{pm}$, even if national stock exchanges are closed. We report the results of this analysis in table 10. The effects of smartphones vs. other trading platforms are significantly stronger during after-hours (panel B) as compared to market-hours (panel A). Averaging across all outcomes, our estimates are $80 \%$ higher during after-hours, ranging from a $27 \%$ increase for skewness of assets purchased to a $175 \%$ increase for the probability of buying lottery stocks. 
Stronger effects during after-hours are consistent with smartphones facilitating trades based more on system 1 thinking (Kahneman,2011). During after-hours, investors are more likely to be out of the workplace and in more informal locations such at home or at restaurants. Moreover, later in the day investors are also more prone to the effects of decision fatigue (Baumeister et al., 1988). For these reasons, investors could be more likely to rely on the more immediate and automatic system 1 thinking and to avoid system 2 thinking that requires more conscious effort, energy and attention. Smartphones appear to facilitate or foster this higher reliance on system 1 .

A potential concern with this interpretation of our evidence is that institutional features could be systematically different when trading during market hours vs. after-hours, when markets are closed. These different institutional features-and not a higher reliance on system 1-could drive our results. To help address this concern, we run a falsification test by estimating smartphone effects in the morning, between 8am and 9am. During this hour markets are still closed in Germany. Nonetheless, earlier in the morning investors are less likely to be in more relaxed environments and should not suffer decision fatigue. If institutional features drive our results we would expect to find similar results during after-hours and this morning hour. Alternatively, if higher reliance on system 1 drives our results, we would expect stronger smartphone effects during after-hours. Consistent with this latter interpretation, we document in panel $C$ that smartphone effects are very similar in the morning hour and in market hours, but weaker than the effects of trades during after-hours.

Although investors do not trade via smartphones more frequently at specific hours, the effects of this new technology are stronger in trades during after-hours, when investors rely more on system 1 thinking. Collectively, this evidence suggests that hours-of-the-day effects can contribute to explain, but not fully account for our evidence. That is, even within the same trading hours, investors are more likely to buy riskier, lottery-type, and 
hot assets.

\subsection{Do investors use smartphones to trade different asset classes?}

Investors could use smartphones to trade specific asset classes. This selection effect could drive our results. We test for this possibility by including in our main specifications asset-class-by-year fixed effects. For this analysis, we classify assets into six categories: individual stocks, bonds, mutual funds, warrants, certificates, and options. While the economic magnitudes are attenuated, smartphone effects are economically and statistically significant also in trades within the same asset class, in the same year. For example, the volatility of the assets purchased increases by $2.5 \%$ or $11.4 \%$ of the unconditional mean for smartphone users (22\%). Analogously, the probability of buying lottery-type assets increases by $2.4 \mathrm{pp}$, or $20.0 \%$ of the unconditional mean. Although important, asset-class effects cannot fully account for our results. Even within the same asset class, investors when using smartphones are more likely to purchase assets that are riskier, with lotterytype characteristics, and that have recently performed very well. ${ }^{12}$

\subsection{Do digital nudges drive our results?}

Choice architecture and nudges can significantly affect economic decisions, from personal investments to saving for retirement, from credit cards to mortgages (for a review see Thaler and Sunstein, 2008). Smartphone apps are very effective in nudging consumers and changing their consumption and spending behaviors (Levi and Benartzi, 2020; D'Acunto, Rossi, and Weber, 2020). Analogously, investing apps can influence behaviors by using push notifications or by giving more salience to specific information. For example, the

\footnotetext{
${ }^{12}$ When we run specifications with both hour-of-the-day and asset-class fixed effects, we find smaller but still economically and statistically significant smartphone effects. We report these results in the Appendix Table A3.
} 
Robinhood trading app prominently features the winning and losing stocks of the previous day. ${ }^{13}$ Welch (2020) and Barber et al. (2020) document that Robinhood investors are more likely to buy top winners and top losers. Thus prominently displaying "top mover" stocks in the app could contribute to generate these trading patterns. Similarly, in our setting information displayed in the smartphone app could mechanically generate trades that favor riskier and lottery-type assets, and past winners.

To directly test for the effects of digital nudges on our results, we would need to observe how information is displayed on the mobile apps vs. on other platforms. This information is only partially available to us. ${ }^{14}$ Therefore, we overcome this data limitation by running a falsification test. Given that smartphone apps tend to prominently feature only individual stocks, we investigate if our smartphone effects are present also in other asset classes such as mutual funds and options. If digital nudges drive our results, we would expect smartphone effects to be stronger or only present in individual stocks and weaker or not present at all in the other asset classes.

Our findings in table 11 document that the inclusion of asset-class-by-year fixed effects does not fully explain our results. While this evidence is consistent with not one specific asset class driving our results, we cannot rule out that smartphone effects are stronger in individual stocks vs. other asset classes. In table 12, we more directly test for these heterogeneous effects. In practice, we run our main specifications with investor-by-month fixed effects separately for different asset classes: individual stocks, mutual funds, and other classes (certificates, options and warrants). In panel A, we document that smartphone effects are economically and statistically significant for all our outcomes in trades related to individual stocks. More importantly, in panel B, we document similarly strong-if

\footnotetext{
${ }^{13}$ Under the recent news, Robinhood display the "Top Movers" list which presents the four stocks with highest absolute return since the market close of the previous day. By clicking on the "Show More" option, the investors could see an expanded list of the 20 stocks with the largest price movements.

${ }^{14}$ While we are able to observe the current app for one of the two banks, we don't know the information display when the app was first introduced and if any meaningful change has happened.
} 
anything stronger-effects for trades in mutual funds. This evidence suggests that digital nudges, such as saliently featuring winner stocks, are not likely to drive our results. Evidence from trades in other asset classes such as options and warrants confirm this interpretation. Although our sample is limited to few thousand observations and only one of the results (volatility of assets purchased) is statistically significant at the $1 \%$ level, our point estimates are all positive and similar in magnitude to the estimates in other asset classes.

Collectively, these findings suggest that digital nudges do not drive the smartphone effects we document. One could argue that even if these nudges were to mechanically drive our results, they are features of the smartphone app and, ultimately, just the channel through which smartphones influence trading behavior. While documenting this channel would still be interesting, showing that smartphones have effects above and beyond automatic nudges has more profound implications. First, given that each smartphone app has specific features and potentially employs different nudges, our results-not being driven by any specific nudge-are more likely to generalize to smartphone trading apps in general. Second, the policy implications are starkly different. If digital nudges drive trading behavior, regulating them could limit the effects of smartphones. Alternatively, if these nudges are not the only major driver of trading behaviors, any policy intervention regulating the choice architecture in these apps might not be as effective as hoped.

\subsection{Does device screen size drive our results?}

Smartphones have a smaller screen, where information can be more difficult to navigate and where more prominent features can capture much of the investor attention. This physical attribute of smartphones can exacerbate existing trading biases or create new ones (for a review see Benartzi and Lehrer, 2015). Therefore, we test if smartphone smaller screen size contributes to our results. 
For the years 2010 to 2014 for one bank, we can observe if trades occur through smartphone (iPhone), iPad, or desktop, thus providing variation in the device screen size. In this analysis, we estimate the effect of smartphones and iPads separately by comparing them to other platforms. ${ }^{15}$ We report our results in table 13. In panel A we include individual and year fixed effects, while in panel B we include only year fixed effects. We do not have enough power to include individual-by-month fixed effects as in our previous analyses, because such estimates would be based only on those investors who trade in the same month using at least three platforms, that is a smartphone, an iPad, and a desktop (or other platform). The estimates in panel A are less restrictive as they use only variation from those investors who make at least one trade across the three different platforms anytime during our sample period. Using this specification, we find that both iPhones and iPads increase the likelihood of buying riskier and lottery-type assets, and trend chasing. The magnitudes are very similar for risky assets and, possibly, stronger in iPad trades for lottery-type assets and past winners.

The estimates in panel A are identified by comparing trades of the same investors across devices with different screen sizes. Nonetheless, investors that use three different platforms could be a non-representative sample of the other traders at the two banks. In other words, gains in terms of identification could come at the expense of external validity of these results. To address this trade-off, in Panel B we include only year fixed effects and we exploit both within- and across-individual variation. Consistent with out results in panel A, we find also in this specification that the effects of iPhones and iPad are very similar across all our outcome variables.

Collectively, this evidence suggests that the smaller screen size of smartphones does not drive our main results. Our findings are consistent with evidence in Liao et al. (2020) that differences in the devices' physical attributes per se do not drive investor behavior in

\footnotetext{
${ }^{15}$ In our main analyses, the smartphone platform included both smartphones and tablets such as iPads.
} 
a peer-to-peer lending platform.

\subsection{Are smartphone effects transitory?}

Last, we investigate the dynamics of smartphone effects. Do investors get excited about this new technology and temporarily change their behavior? Or are smartphone effects persistent over time? If investors heavily rely on this new technology just in the few months after the adoption, our estimates might overstate the relevance of smartphone effects. By relying on investor-by-time fixed effects, our results reflect in fact only trading behavior in those months when investors actively use smartphones to trade.

We provide a graphical representation of the results of this analysis in figure 4 . We plot the interaction of the indicator for smartphone trades in equation 1 with indicators for the quarters after the adoption of smartphone trading. We include in all our specifications investor-by-month fixed effects. In panel A, we report results for the probability of buying risky assets. The effects of smartphones are stable from the first quarter of usage up to quarter nine or afterwards. The effects on volatility (panel B) and skewness of trades (panel C), and probability of purchasing past winners (panel D) are also stable over time.

Overall, this evidence suggests that investors' initial excitement or willingness to experiment riskier and more gambling-type trades via smartphones are not driving our results. The effect of smartphones does not appear to be short-lived and transitory.

\section{Conclusion}

Smartphones represent one of the most widely used technologies, with over 250 million devices in the US alone. Large online brokers report that over $20 \%$ of all retail investor annual trades have been executed using mobile devices and estimate this percentage to 
double in the next few years. ${ }^{16}$

Using a novel data set from two large German retail banks, we investigate if and how smartphones influence investors. Comparing trades done by the same investor in the same month across different platforms, we document that traders on smartphone buy more risky assets, chase higher volatility and higher skewness investments, and lotterytype assets. Moreover, investors are more likely to buy past winners.

We conduct several additional analyses to better understand the mechanism behind these results. Although investors are not more likely to use this new technology at specific hours of the day, smartphone effects are stronger during after-hours. The selection of specific times of the day or specific asset classes when using smartphones contribute-but do not fully explain-our results. After using smartphones, investors start buying higher volatility, higher skewness, more lottery-type assets also in their non-smartphone trades. This evidence helps to rule out substitution effects across different platforms.

Collectively, our evidence suggests that investors make more intuitive (system 1type) decisions while using smartphones. This tendency leads to increased risk-taking, gambling-like activity, and more trend chasing. Previous studies have linked these trading behaviors to lower portfolio efficiency and performance. Therefore, the convenience of smartphone trading might come at a cost for many retail investors.

\footnotetext{
${ }^{16}$ Sources:https:/ /www.statista.com/topics/2711/us-smartphone-market/; https:/ / www.cnbc.com/2018/11/29/td-ameritrade-sees-more-people-trading-on-their-phones.html
} 


\section{References}

[1] Bali, T., D. A. Hirshleifer, L. Peng and Y. Tang. 2019. Attention, Social Interaction, and Investor Attraction to Lottery Stocks Working Paper.

[2] Barber, B. M., and T. Odean. 2002. Online Investors: Do the slow die first? Review of Financial Studies 15:455-87.

[3] Barber, B. M., X. Huang, T. Odean, and C. Schwarz. 2020. Attention Induced Trading and Returns: Evidence from Robinhood Users Working Paper.

[4] Baumeister, R., Bratslavsky,E., Muraven, M., and D. M. Tice. 1988. Ego depletion: Is the active self a limited resource? Journal of Personality and Social Psychology 74(5):12521265 .

[5] Benartzi, S. and J. Lehrer. 2015. The Smarter Screen: Surprising Ways to Influence and Improve Online Behavior. Penguin Books, New York.

[6] Benartzi, S. and R. H. Thaler. 1995. Myopic Loss Aversion and the Equity Premium Puzzle. The Quarterly Journal of Economics, 110(1),73-92.

[7] Buchak, G., G. Matvos, T. Piskorski, and A. Seru. 2018. Fintech, Regulatory Arbitrage, and the Rise of Shadow Banks. Journal of Financial Economics, forthcoming.

[8] Cen, X., 2019. Going Mobile, Investor Behavior, and Financial Fragility (December 15, 2019). Working Paper, Available at SSRN: https: / / ssrn.com/abstract=3312411

[9] Choi, J. J., D. Laibson, and A. Metrick. 2002. How does the Internet affect trading? Evidence from investor behavior in 401(k) plans, Journal of Financial Economics 64:397421.

[10] D'Acunto, F., N. Prabhala and A. Rossi. 2019. The Promises and Pitfalls of RoboAdvising The Review of Financial Studies, Forthcoming.

[11] D'Acunto, F., Rossi, A. G., and M. Weber. 2020. Crowdsourcing Peer Information to Change Spending Behavior. Chicago Booth Research Paper No. 19-09, FamaMiller Working Paper, Available at SSRN: https://ssrn.com/abstract=3339335 or http://dx.doi.org/10.2139/ssrn.3339335

[12] Di Maggio, M., and V. Yao. 2019. FinTech Borrowers: Lax-Screening or CreamSkimming? Working Paper .

[13] Fos, V., N. Hamdi, A. Kalda, and J. Nickerson. 2019. Gig-Labor: Trading Safety Nets for Steering Wheels. Working Paper.

[14] Fuster, A., Plosser, M., Schnabl, P. and J. Vickery. 2018. The role of technology in mortgage lending. The Review of Financial Studies, forthcoming. 
[15] Gargano, A. and A. Rossi. 2018. Does It Pay to Pay Attention?, Review of Financial Studies 31,12:4595-4649.

[16] Haigh, M. S. and J. A. List. 2005. Do Professional Traders Exhibit Myopic Loss Aversion? An Experimental Analysis, Journal of Finance 60,1:523-534.

[17] Jackson, E., 2019. Availability of the gig economy and long run labor supply effects for the unemployed, Working Paper.

[18] Kahneman, D., 2003. A perspective on judgement and choice. American Psychologist 58(9):697-720.

[19] Kahneman, D., 2011. Thinking, Fast and Slow. New York :Farrar, Straus and Giroux.

[20] Koustas, D., 2018, Consumption insurance and multiple jobs: Evidence from rideshare drivers. Working Paper.

[21] Kumar, A. 2009. Who Gambles in the Stock Market?, Journal of Finance 64,4:1889-1933.

[22] Levi, Y. and S. Benartzi, 2020. Mind the App: Mobile Access to Financial Information and Consumer Behavior. Working Paper, Available at SSRN: https://ssrn.com/abstract=3557689 or http:/ /dx.doi.org/10.2139/ssrn.3557689

[23] Liao, L., Wang, Z., Xiang, J., Yan, H., and J. Yang. 2020. User interface and firsthand experience in retail investing. The Review of Financial Studies, forthcoming.

[24] Loos, B., Previtero, A., Scheurle, S., and A. Hackethal, 2020. Robo-advisers and investor behavior. Working Paper.

[25] Linnainmaa, J., B. Melzer, and A. Previtero,. 2020. The Misguided Beliefs of Financial Advisors, Journal of Finance forthcoming.

[26] Stanovich, K. E. and R. F. West, 2000. Individual difference in reasoning: Implications for the rationality debate?. Behavioral and Brain Sciences 23(5):645-726.

[27] Thaler, R. H., and C. R. Sunstein. 2008. Nudge: Improving decisions about health, wealth, and happiness. Yale University Press.

[28] Welch. 2020. Retail Raw: Wisdom of the Robinhood Crowd and the Covid Crisis. Working Paper. 
Figure 1:

Smartphone Usage

This figure plots the fraction of trades that occur over smartphones through time. Panel A plots this usage for the entire sample while Panel B plots this conditional for investors who use the smartphone.

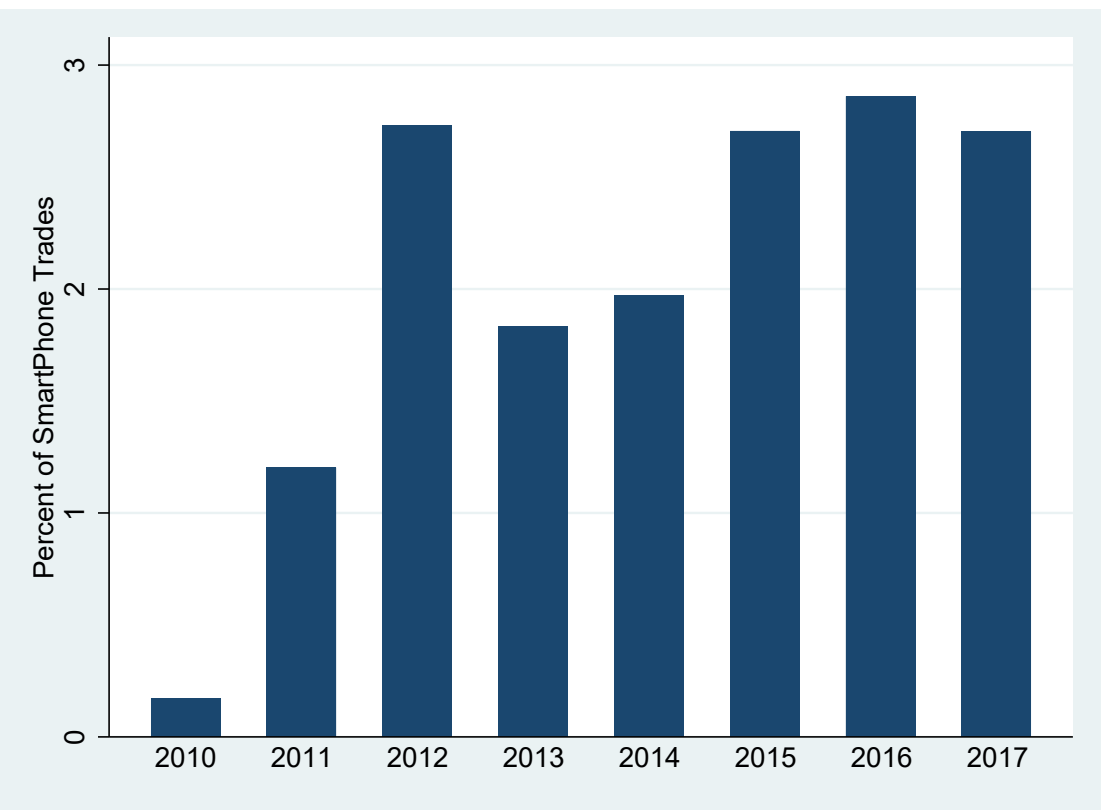

Panel A

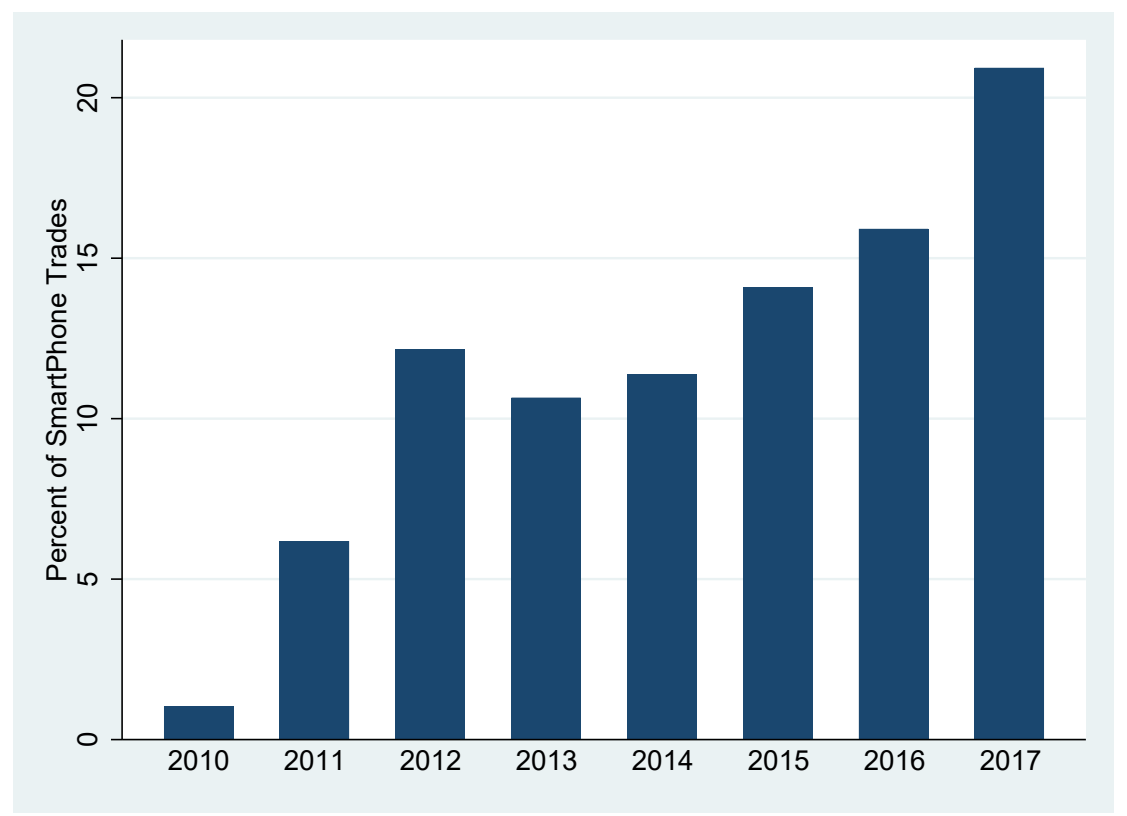

Panel B 


\section{Figure 2:}

Trading Hour Density

This figure plots density for hour of the day that trade occurs. Panel A plots this for the sample while Panel B compares this density for phone users versus non-users. Panel C plots this density for phone users and compares smartphone and non-phone trades.

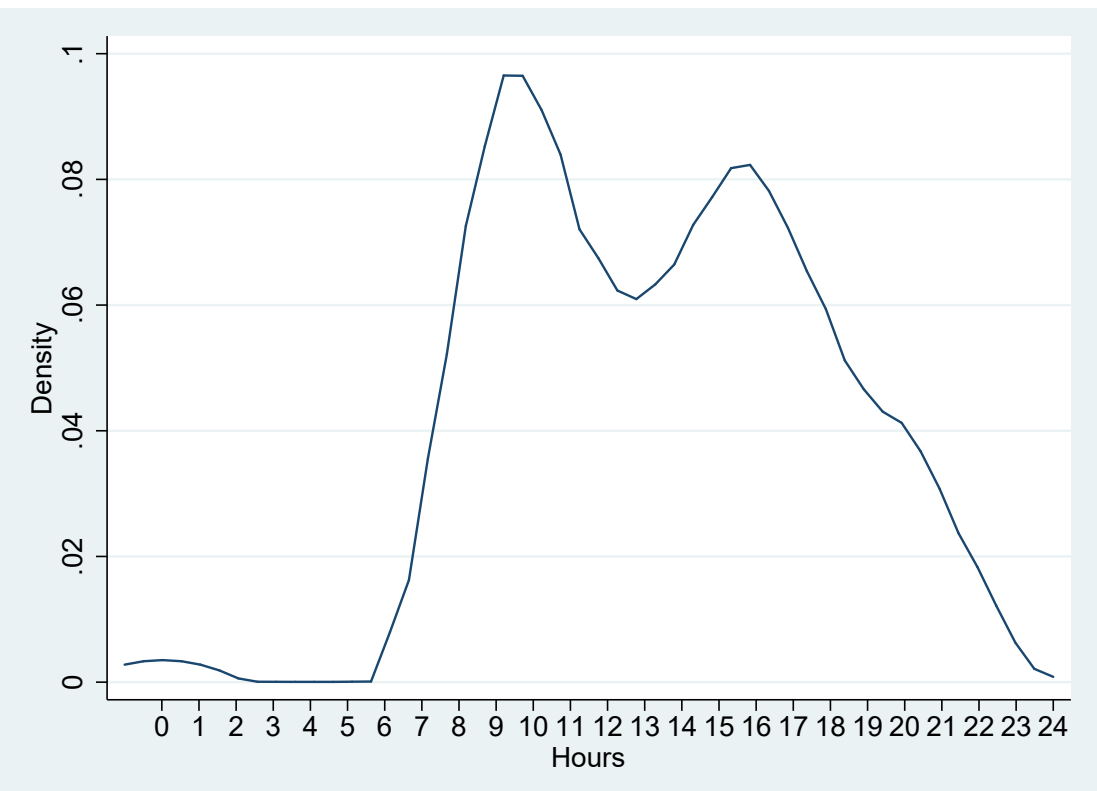

Panel A

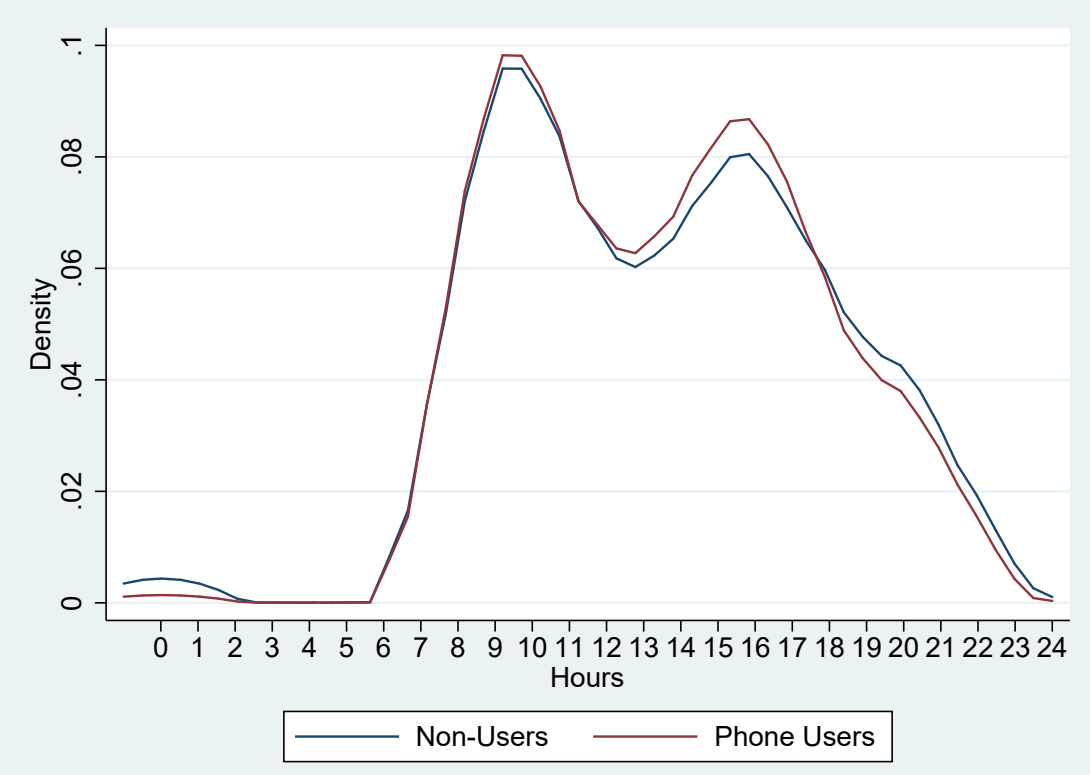

Panel B 


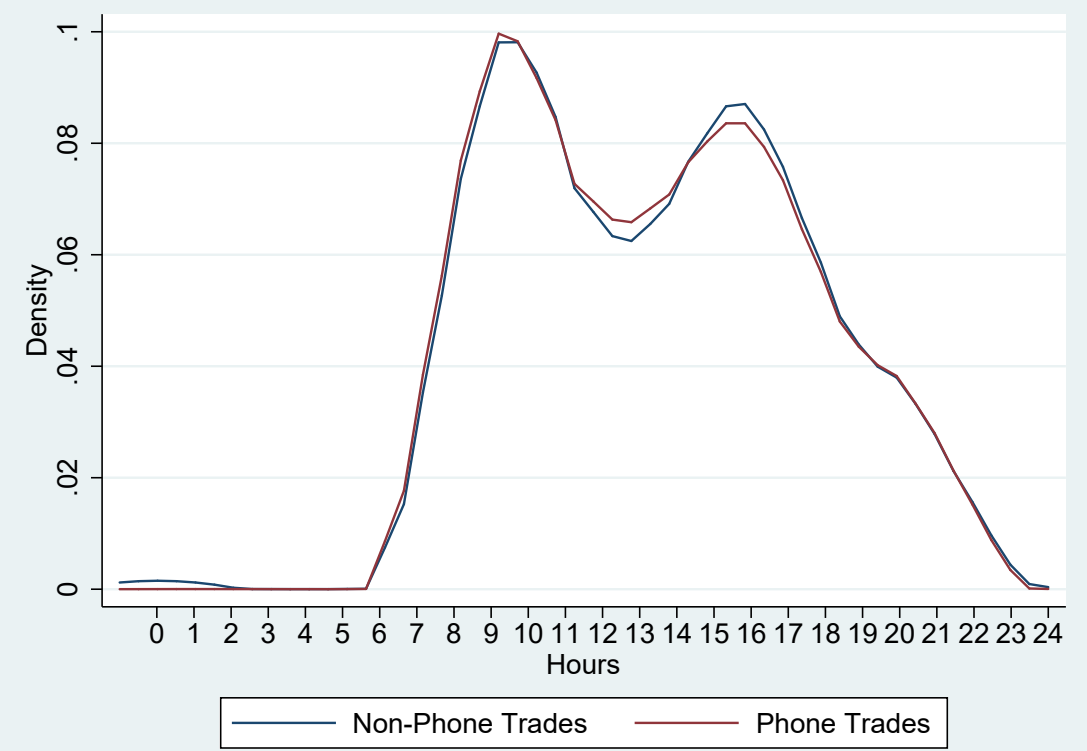

Panel C 


\section{Figure 3:}

Spillover Effects: Dynamics

This figure plots the dynamics of the spillover effects on other trades estimated using difference-in-differences regressions. The first difference comes from before and after launch date of smartphone app while the second difference comes from the type of smartphone an investor owns (e.g. iPhone vs android). Each coefficient represents the effect of the use of smartphone on risk taking by the same individual on other platforms for different quarters relative to the launch date of the trading app. The outcome variables include Probability of purchasing risky assets (panel A), volatility (panel B), skewness (panel C) of assets purchased, and probability of purchasing top 10 percentile performers (panel D). The confidence intervals are plotted at 5\% levels.

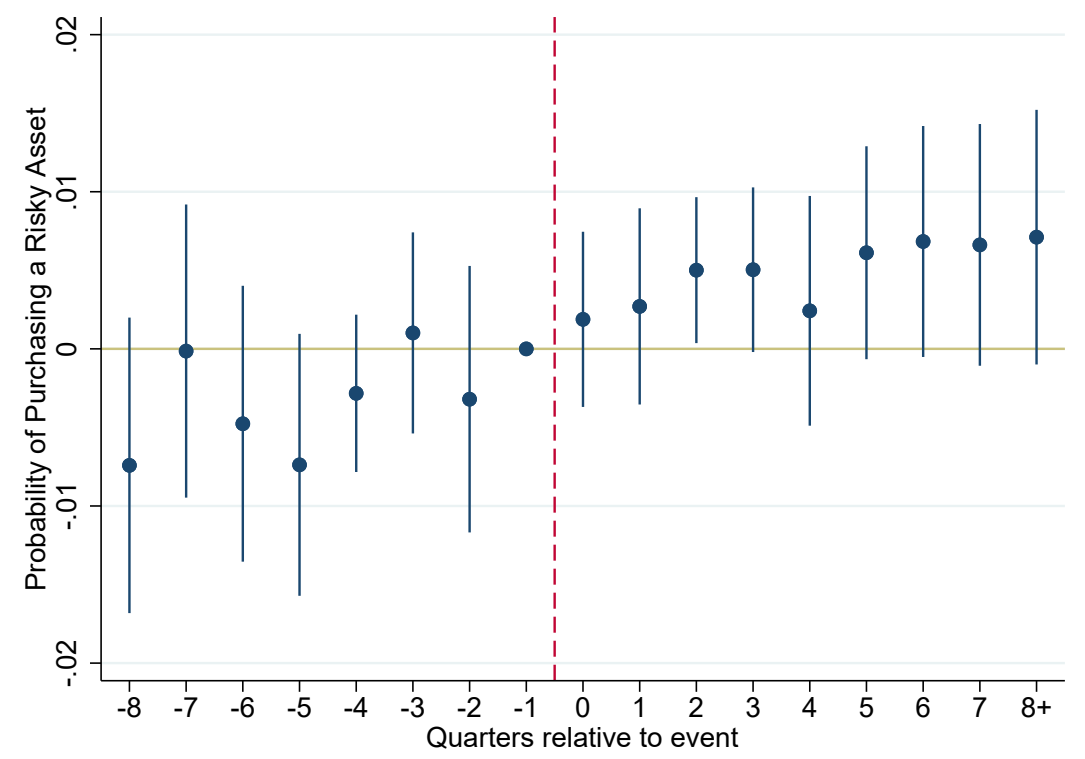

Panel A

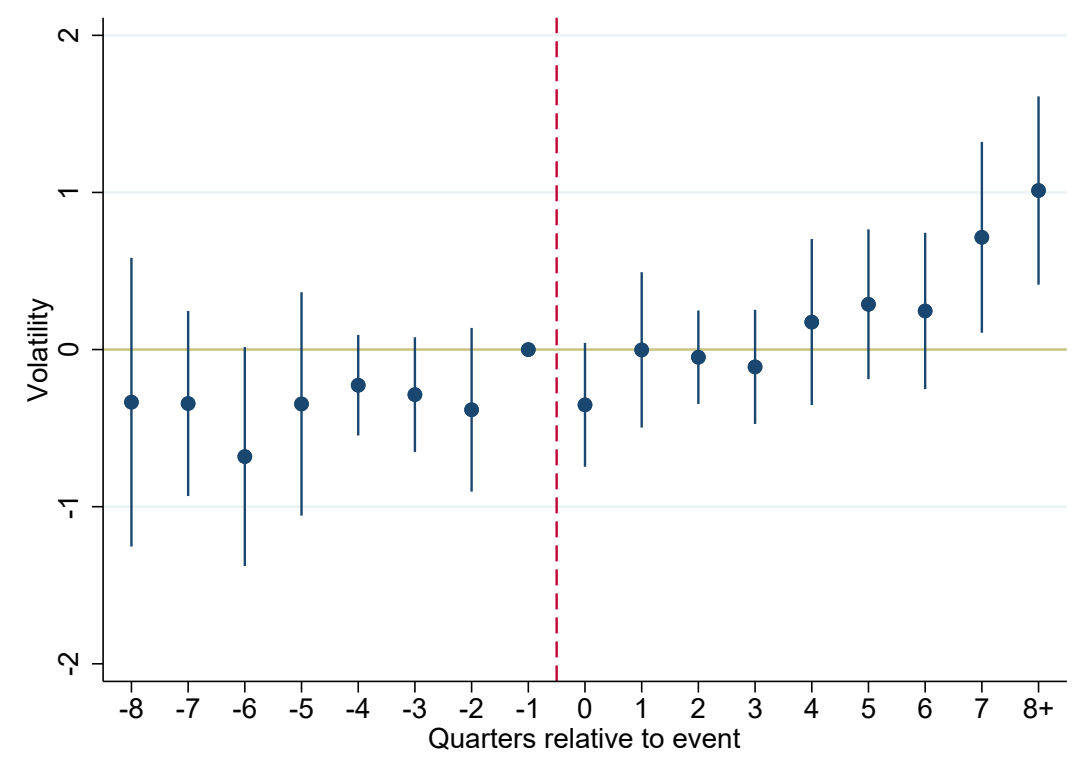

Panel B 


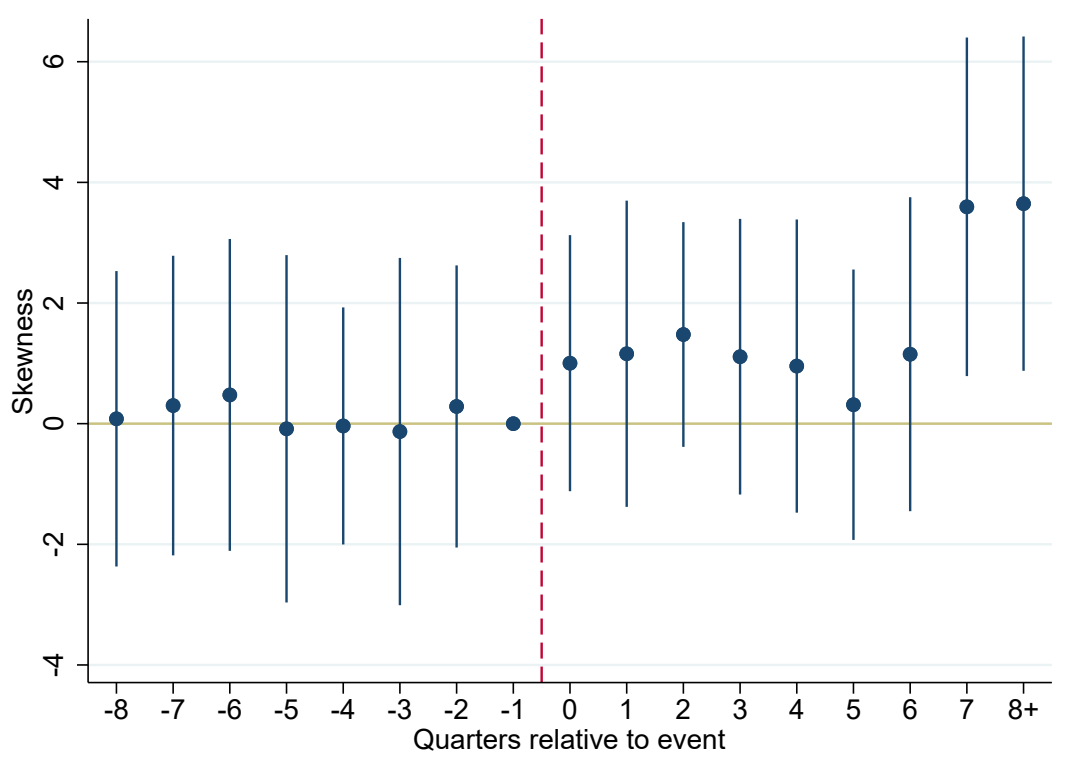

Panel C

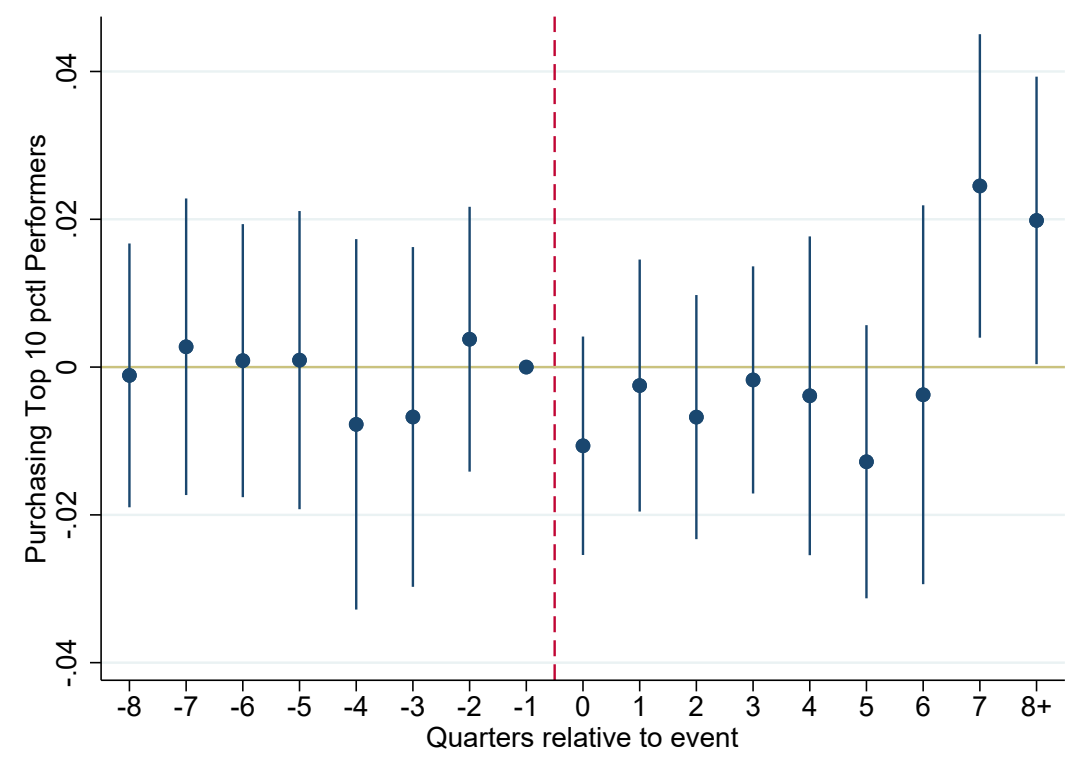

Panel D 


\section{Figure 4:}

Dynamics of Smartphone Effects

This figure plots the dynamics of our effects relative to the first use of smartphone. Each coefficient represents the effect of the use of smartphone on risk taking for different quarters relative to the first use. The outcome variables include Probability of purchasing risky assets (panel A), volatility (panel B), skewness (panel C) of assets purchased, and probability of purchasing top 10 percentile performers (panel D). The confidence intervals are plotted at 5\% levels.

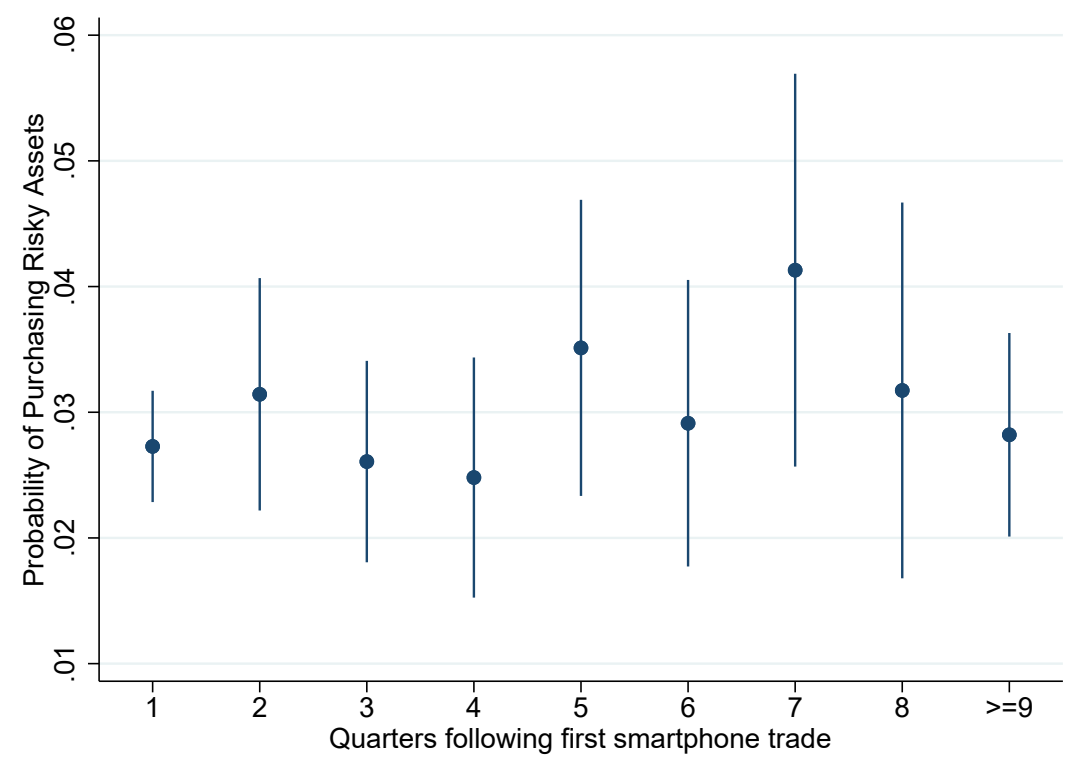

Panel A

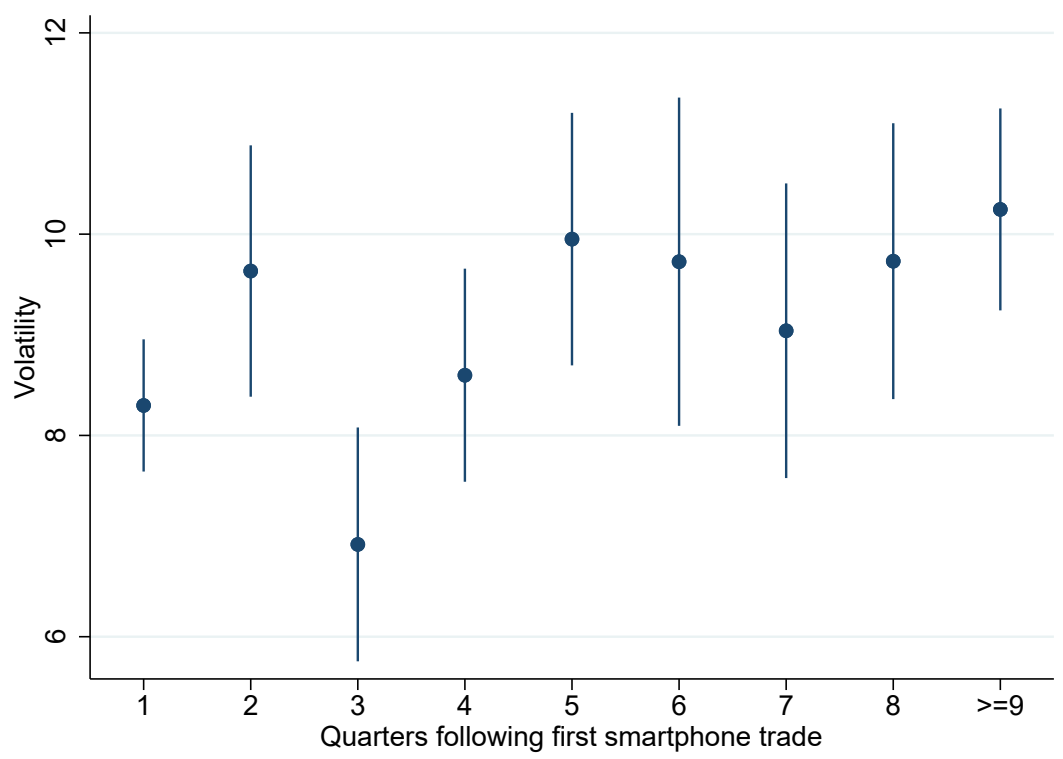

Panel B 


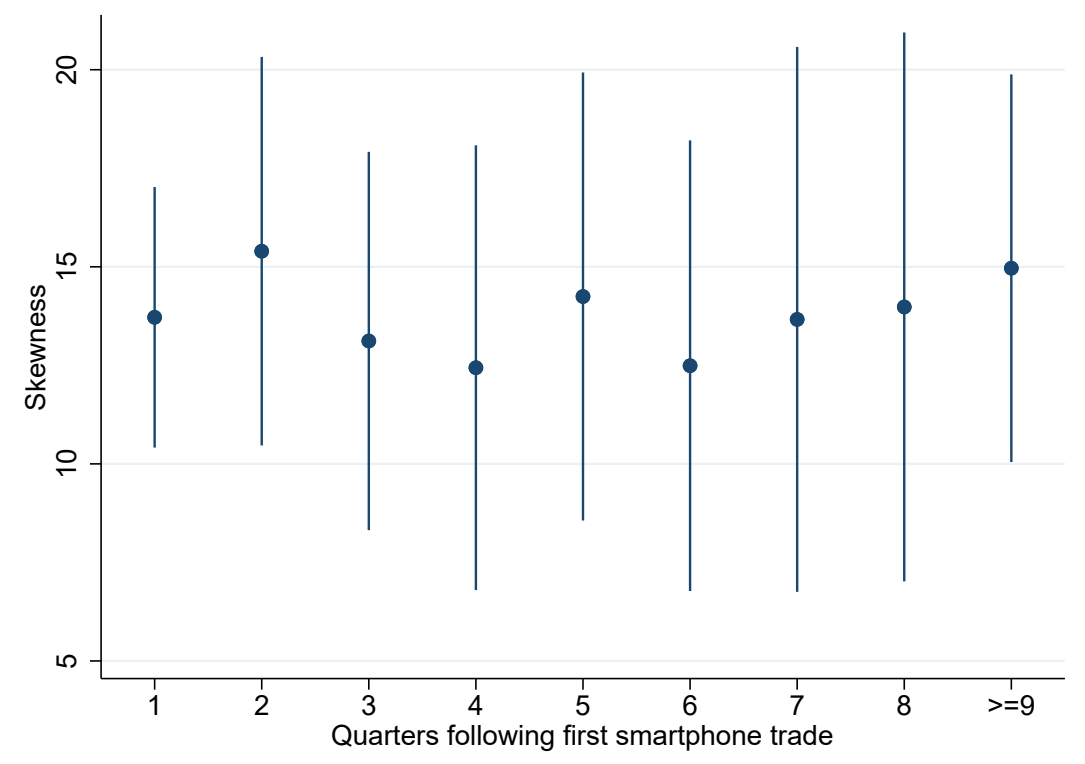

Panel C

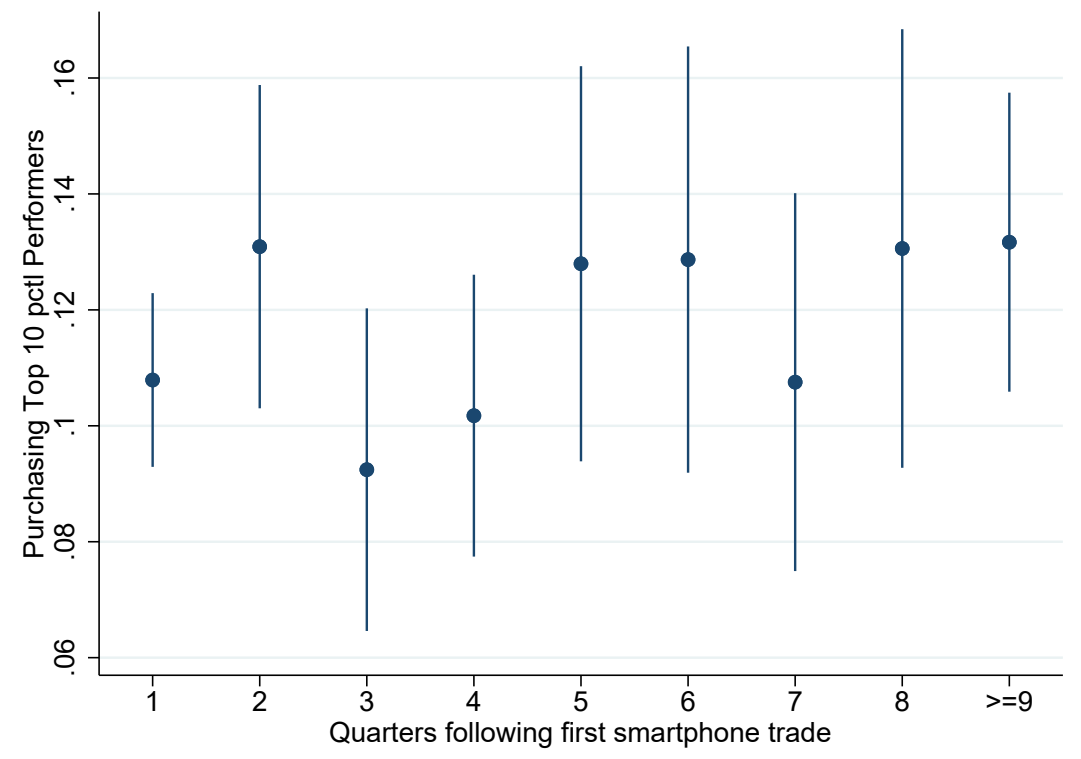

Panel D 
Table 1:

Summary Stats

This table reports the summary statistics of variables used in our analysis.

\begin{tabular}{lccccc}
\hline & & & & & \\
& Mean & Std.Dev. & p25 & Median & p75 \\
\hline Smartphone & 0.02 & 0.15 & 0.00 & 0.00 & 0.00 \\
Prob of Purchasing Risky Assets & 0.93 & 0.23 & 1.00 & 1.00 & 1.00 \\
Volatility of Assets Purchased & 17.27 & 13.14 & 8.71 & 13.70 & 21.32 \\
Skewness of Assets Purchased & -7.92 & 55.56 & -38.64 & -7.46 & 24.16 \\
Prob of Purchasing Lottery type Assets & 0.07 & 0.23 & 0.00 & 0.00 & 0.00 \\
Prob of Purchasing Top 50 pctl performers & 0.68 & 0.40 & 0.38 & 1.00 & 1.00 \\
Prob of Purchasing Top 40 pctl performers & 0.61 & 0.42 & 0.00 & 0.75 & 1.00 \\
Prob of Purchasing Top 30 pctl performers & 0.46 & 0.42 & 0.00 & 0.50 & 1.00 \\
Prob of Purchasing Top 20 pctl performers & 0.29 & 0.38 & 0.00 & 0.00 & 0.50 \\
Prob of Purchasing Top 10 pctl performers & 0.11 & 0.27 & 0.00 & 0.00 & 0.00 \\
Risk Categories of Assets Purchased & 3.99 & 0.72 & 3.50 & 4.00 & 4.50 \\
Prob of Purchasing a Warrant & 0.09 & 0.26 & 0.00 & 0.00 & 0.00 \\
Prob of Purchasing a Certificate & 0.03 & 0.16 & 0.00 & 0.00 & 0.00 \\
\hline
\end{tabular}


Table 2:

Who uses Smartphones?

This table compares investors who used smartphones to trade to those who never used smartphones to trade.

Panel A

\begin{tabular}{lcccc}
\hline & \multicolumn{2}{c}{ Phone Users } & \multicolumn{2}{c}{ Non Users } \\
& Mean & Median & Mean & Median \\
\hline Avg No of Trades per Month & 10.01 & 3.00 & 5.32 & 2.00 \\
Avg Value of Trades & $4,477.11$ & $1,895.00$ & $3,812.90$ & $1,000.00$ \\
Prob of Purchasing Risky Assets & 0.95 & 1.00 & 0.92 & 1.00 \\
Volatility of Assets Purchased & 22.01 & 17.78 & 16.52 & 13.13 \\
Skewness of Assets Purchased & -5.61 & -5.09 & -9.02 & -8.48 \\
Prob of Purchasing Lottery type Assets & 0.12 & 0.00 & 0.07 & 0.00 \\
Prob of Purchasing Top 10 pctl performers & 0.17 & 0.00 & 0.10 & 0.00 \\
Risk Categories of Assets Purchased & 4.12 & 4.00 & 3.97 & 4.00 \\
Prob of Purchasing a Warrant & 0.19 & 0.00 & 0.07 & 0.00 \\
Prob of Purchasing a Certificate & 0.04 & 0.00 & 0.03 & 0.00 \\
\hline
\end{tabular}

Panel B

\begin{tabular}{lcccc}
\hline & \multicolumn{2}{c}{ Phone Users } & \multicolumn{2}{c}{ Non Users } \\
& Mean & Median & Mean & Median \\
\hline Income Bin [20k,60k) & 0.60 & 1.00 & 0.60 & 1.00 \\
Income Bin [60k,100k) & 0.32 & 0.00 & 0.32 & 0.00 \\
Income Bin [>=100k] & 0.09 & 0.00 & 0.08 & 0.00 \\
Wealth Bin [20k,60k) & 0.75 & 1.00 & 0.80 & 1.00 \\
Wealth Bin [60k,100k) & 0.09 & 0.00 & 0.08 & 0.00 \\
Wealth Bin [>=100k] & 0.17 & 0.00 & 0.12 & 0.00 \\
Years since Member & 8.71 & 9.32 & 9.82 & 9.32 \\
Age & 44.85 & 45.00 & 52.61 & 52.00 \\
Female & 0.05 & 0.00 & 0.18 & 0.00 \\
\hline
\end{tabular}




\section{Table 3:}

Probability of Purchasing Risky Assets

This table reports estimates of the regressions that examine the effect of the use of smartphones on risk taking as measured by the probability of purchasing risky assets. Each observation corresponds to individual $\mathrm{x}$ month $\mathrm{x}$ trading device level where trading device has been categorized into two groups - smartphone and all other devices. All outcome variables are aggregated from the trade-level data to the observation-level as average values and different columns include different fixed effects as indicated. Standard errors are double-clustered at individual and month level, and t-statistics are reported in parentheses. ${ }^{*}, * *$ and ${ }^{* * *}$ represent significance at $10 \%, 5 \%$ and $1 \%$ level, respectively.

\begin{tabular}{lcccc}
\hline & \multicolumn{4}{c}{ Probability of Purchasing Risky Assets } \\
& $(1)$ & $(2)$ & $(3)$ & $(4)$ \\
\hline Smartphone & $0.05^{* * *}$ & $0.02^{* * *}$ & $0.03^{* * *}$ & $0.04^{* * *}$ \\
& $(20.22)$ & $(13.07)$ & $(15.54)$ & $(17.73)$ \\
Individual FE & No & Yes & No & No \\
Year FE & No & Yes & No & No \\
Individual x Year FE & No & No & Yes & No \\
Individual x Month FE & No & No & No & Yes \\
\hline Observations & 1595097 & 1575443 & 1524956 & 636922 \\
$R^{2}$ & 0.001 & 0.684 & 0.670 & 0.499 \\
\hline
\end{tabular}


Table 4:

Volatility of Assets Purchased

This table reports estimates of the regressions that examine the effect of the use of smartphones on risk taking as measured by the volatility of purchased assets calculated using 12month rolling window as annualized standard deviation. Each observation corresponds to individual $x$ month $x$ trading device level where trading device has been categorized into two groups - smartphone and all other devices. All outcome variables are aggregated from the trade-level data to the observation-level as average values and different columns include different fixed effects as indicated. Standard errors are double-clustered at individual and month level, and t-statistics are reported in parentheses. ${ }^{*},{ }^{* *}$ and ${ }^{* * *}$ represent significance at $10 \%, 5 \%$ and $1 \%$ level, respectively.

\begin{tabular}{lcccc}
\hline & \multicolumn{5}{c}{ Volatility of Assets Purchased } \\
& $(1)$ & $(2)$ & $(3)$ & $(4)$ \\
\hline Smartphone & $12.07^{* * *}$ & $4.43^{* * *}$ & $6.66^{* * *}$ & $9.28^{* * *}$ \\
& $(10.62)$ & $(10.00)$ & $(16.05)$ & $(12.19)$ \\
Individual FE & No & Yes & No & No \\
Year FE & No & Yes & No & No \\
Individual x Year FE & No & No & Yes & No \\
Individual x Month FE & No & No & No & Yes \\
\hline Observations & 2326852 & 2309186 & 2270342 & 1320533 \\
$R^{2}$ & 0.012 & 0.633 & 0.560 & 0.479 \\
\hline
\end{tabular}




\section{Table 5:}

Skewness of Assets Purchased

This table reports estimates of the regressions that examine the effect of the use of smartphones on risk taking as measured by the skewness of purchased assets calculated using 12-month rolling window. Each observation corresponds to individual $\mathrm{x}$ month $\mathrm{x}$ trading device level where trading device has been categorized into two groups - smartphone and all other devices. All outcome variables are aggregated from the trade-level data to the observation-level as average values and different columns include different fixed effects as indicated. Standard errors are double-clustered at individual and month level, and t-statistics are reported in parentheses. ${ }^{*},{ }^{* *}$ and ${ }^{* * *}$ represent significance at $10 \%, 5 \%$ and $1 \%$ level, respectively.

\begin{tabular}{lcccc}
\hline & \multicolumn{4}{c}{ Skewness of Assets Purchased } \\
& $(1)$ & $(2)$ & $(3)$ & $(4)$ \\
\hline Smartphone & $19.23^{* * *}$ & $5.13^{* *}$ & $10.19^{* * *}$ & $14.40^{* * *}$ \\
& $(3.67)$ & $(2.81)$ & $(4.90)$ & $(3.71)$ \\
Individual FE & No & Yes & No & No \\
Year FE & No & Yes & No & No \\
Individual x Year FE & No & No & Yes & No \\
Individual x Month FE & No & No & No & Yes \\
\hline Observations & 2326695 & 2309032 & 2270186 & 1320331 \\
$R^{2}$ & 0.002 & 0.281 & 0.392 & 0.503 \\
\hline
\end{tabular}


Table 6:

Probability of Purchasing Lottery type Assets

This table reports estimates of the regressions that examine the effect of the use of smartphones on risk taking as measured by the probability of purchasing assets with below median prices but above median volatility and skewness. Each observation corresponds to individual $x$ month $x$ trading device level where trading device has been categorized into two groups - smartphone and all other devices. All outcome variables are aggregated from the trade-level data to the observation-level as average values and different columns include different fixed effects as indicated. Standard errors are double-clustered at individual and month level, and t-statistics are reported in parentheses. ${ }^{*},{ }^{* *}$ and ${ }^{* * *}$ represent significance at $10 \%, 5 \%$ and $1 \%$ level, respectively.

\begin{tabular}{lcccc}
\hline & \multicolumn{4}{c}{ Prob of Purchasing Lottery Type Assets } \\
& $(1)$ & $(2)$ & $(3)$ & $(4)$ \\
\hline Smartphone & $0.10^{* * *}$ & $0.03^{* * *}$ & $0.05^{* * *}$ & $0.08^{* * *}$ \\
& $(7.32)$ & $(7.53)$ & $(10.72)$ & $(12.93)$ \\
Individual FE & No & Yes & No & No \\
Year FE & No & Yes & No & No \\
Individual x Year FE & No & No & Yes & No \\
Individual x Month FE & No & No & No & Yes \\
\hline Observations & 2361188 & 2343582 & 2305258 & 1362141 \\
$R^{2}$ & 0.003 & 0.331 & 0.379 & 0.497 \\
\hline
\end{tabular}




\section{Table 7:}

Trend Chasing

This table reports estimates of the regressions that examine the effect of the use of smartphones on trend chasing. The outcome variable is the probability of purchasing an asset that belongs to the top decile based on past 12-month performance. Each observation corresponds to individual $\mathrm{x}$ month $\mathrm{x}$ trading device level where trading device has been categorized into two groups - smartphone and all other devices. All outcome variables are aggregated from the trade-level data to the observation-level as average values and different columns include different fixed effects as indicated. Standard errors are doubleclustered at individual and month level, and t-statistics are reported in parentheses. ${ }^{*}, * *$ and ${ }^{* *}$ represent significance at $10 \%, 5 \%$ and $1 \%$ level, respectively.

\begin{tabular}{lcccc}
\hline & \multicolumn{3}{c}{ Prob of Purchasing Top 10 Pctl Performers } \\
& $(1)$ & $(2)$ & $(3)$ & $(4)$ \\
\hline Smartphone & $0.164^{* * *}$ & $0.059^{* * *}$ & $0.086^{* * *}$ & $0.120^{* * *}$ \\
& $(7.12)$ & $(5.68)$ & $(7.59)$ & $(8.52)$ \\
Individual FE & No & Yes & No & No \\
Year FE & No & Yes & No & No \\
Individual x Year FE & No & No & Yes & No \\
Individual x Month FE & No & No & No & Yes \\
\hline Observations & 2313256 & 2295587 & 2256415 & 1304401 \\
$R^{2}$ & 0.005 & 0.357 & 0.412 & 0.497 \\
\hline
\end{tabular}


Table 8:

Spillover Effects on Other Trades

This table reports estimates of difference-in-differences regressions that examine the association between the use of smartphones and riskiness of assets traded by the same individual on other platforms. The outcome variables include probability of purchasing a risky assets, volatility of purchased assets, skewness of purchased assets and probability of purchasing lottery type assets. Each observation corresponds to individual $x$ month level and captures average risk taking on devices other than smartphones. Panel A considers the first time an individual uses smartphone app as the event date, while Panel B considers the launch date of trading app for different smartphone operating systems as the event date. Standard errors are double-clustered at individual and month level, and t-statistics are reported in parentheses. ${ }^{*},{ }^{* *}$ and ${ }^{* * *}$ represent significance at $10 \%, 5 \%$ and $1 \%$ level, respectively.

Panel A

\begin{tabular}{|c|c|c|c|c|c|}
\hline & $\begin{array}{c}\text { Risky Asset } \\
\text { (1) }\end{array}$ & $\begin{array}{c}\text { Volatility } \\
\text { (2) }\end{array}$ & $\begin{array}{c}\text { Skewness } \\
\text { (3) }\end{array}$ & $\begin{array}{c}\text { Lottery Type } \\
\text { Asset } \\
(4)\end{array}$ & $\begin{array}{c}\text { Top } 10 \text { Pctl } \\
\text { Performers } \\
\quad(5)\end{array}$ \\
\hline Smartphone Use & $\begin{array}{l}0.002 \\
(1.37)\end{array}$ & $\begin{array}{c}0.529^{* * *} \\
(5.75)\end{array}$ & $\begin{array}{c}4.787^{* * * *} \\
(9.44)\end{array}$ & $\begin{array}{c}0.005^{* * * *} \\
(2.64)\end{array}$ & $\begin{array}{l}0.005^{*} \\
(1.78)\end{array}$ \\
\hline Individual FE & Yes & Yes & No & Yes & Yes \\
\hline Month FE & Yes & Yes & Yes & Yes & Yes \\
\hline $\begin{array}{l}\text { Observations } \\
R^{2}\end{array}$ & $\begin{array}{c}302278 \\
0.507\end{array}$ & $\begin{array}{c}427665 \\
0.540\end{array}$ & $\begin{array}{c}428285 \\
0.093\end{array}$ & $\begin{array}{c}287169 \\
0.306\end{array}$ & $\begin{array}{c}279971 \\
0.331\end{array}$ \\
\hline
\end{tabular}

Panel B

\begin{tabular}{|c|c|c|c|c|c|}
\hline & $\begin{array}{c}\text { Risky Asset } \\
\text { (1) }\end{array}$ & $\begin{array}{c}\text { Volatility } \\
\text { (2) }\end{array}$ & $\begin{array}{c}\text { Skewness } \\
\text { (3) }\end{array}$ & $\begin{array}{c}\text { Lottery Type } \\
\text { Asset } \\
(4)\end{array}$ & $\begin{array}{c}\text { Top } 10 \text { Pctl } \\
\text { Performers } \\
\quad(5)\end{array}$ \\
\hline Smartphone Launch & $\begin{array}{c}0.006^{* *} \\
(2.07)\end{array}$ & $\begin{array}{l}0.094 \\
(0.47)\end{array}$ & $\begin{array}{c}3.978^{* * *} \\
(5.01)\end{array}$ & $\begin{array}{l}0.003^{*} \\
(1.93)\end{array}$ & $\begin{array}{l}0.002 \\
(1.32)\end{array}$ \\
\hline Individual FE & Yes & Yes & No & Yes & Yes \\
\hline Month FE & Yes & Yes & Yes & Yes & Yes \\
\hline Observations & 186165 & 248031 & 248324 & 154865 & 149743 \\
\hline$R^{2}$ & 0.478 & 0.496 & 0.090 & 0.287 & 0.314 \\
\hline
\end{tabular}




\section{Table 9:}

Trading Hours

This table reports estimates of the regressions that examine the effect of the use of smartphones on risk taking and trend chasing within the same trading hour. The outcome variables include probability of purchasing a risky assets, volatility of purchased assets, skewness of purchased assets and probability of purchasing lottery type assets. Standard errors are double-clustered at individual and month level, and t-statistics are reported in parentheses. ${ }^{*},{ }^{* *}$ and ${ }^{* *}$ represent significance at $10 \%, 5 \%$ and $1 \%$ level, respectively.

\begin{tabular}{|c|c|c|c|c|c|}
\hline & $\begin{array}{c}\text { Risky Asset } \\
\text { (1) }\end{array}$ & $\begin{array}{c}\text { Volatility } \\
\text { (2) }\end{array}$ & $\begin{array}{c}\text { Skewness } \\
\text { (3) }\end{array}$ & $\begin{array}{c}\text { Lottery Type } \\
\text { Asset } \\
(4)\end{array}$ & $\begin{array}{c}\text { Top } 10 \text { Pctl } \\
\text { Performers } \\
\text { (5) }\end{array}$ \\
\hline Smartphone & $\begin{array}{c}0.014^{* * * *} \\
(4.58)\end{array}$ & $\begin{array}{c}3.475^{* * *} \\
(9.23)\end{array}$ & $\begin{array}{c}7.573^{* * *} \\
(5.84)\end{array}$ & $\begin{array}{c}0.032^{* * *} \\
(5.27)\end{array}$ & $\begin{array}{c}0.046^{* * * *} \\
(5.63)\end{array}$ \\
\hline Individual x Month FE & Yes & Yes & Yes & Yes & Yes \\
\hline Trading Hour x Year FE & Yes & Yes & Yes & Yes & Yes \\
\hline Observations & 33689 & 48879 & 48865 & 51441 & 47873 \\
\hline$R^{2}$ & 0.547 & 0.630 & 0.565 & 0.580 & 0.583 \\
\hline
\end{tabular}


Table 10:

Trading During Market Hours vs. After-hours

This table reports estimates of the regressions that examine how the effect of the use of smartphones on risk taking varies with trading hours. The outcome variables include probability of purchasing a risky assets, volatility of purchased assets, skewness of purchased assets and probability of purchasing lottery type assets. Standard errors are double-clustered at individual and month level, and t-statistics are reported in parentheses. ${ }^{*},{ }^{* *}$ and ${ }^{* * *}$ represent significance at $10 \%, 5 \%$ and $1 \%$ level, respectively. Different panels represent different times of the day.

Panel A: Market Hours

\begin{tabular}{|c|c|c|c|c|c|}
\hline & $\begin{array}{c}\text { Risky Asset } \\
\text { (1) }\end{array}$ & $\begin{array}{c}\text { Volatility } \\
\text { (2) }\end{array}$ & $\begin{array}{c}\text { Skewness } \\
\text { (3) }\end{array}$ & $\begin{array}{c}\text { Lottery Type } \\
\text { Asset } \\
(4)\end{array}$ & $\begin{array}{c}\text { Top } 10 \text { Pctl } \\
\text { Performers } \\
\text { (5) }\end{array}$ \\
\hline Smartphone & $\begin{array}{c}0.013^{* * *} \\
(2.87)\end{array}$ & $\begin{array}{c}2.478^{* * *} \\
(5.75)\end{array}$ & $\begin{array}{c}6.915^{* * *} \\
(4.79)\end{array}$ & $\begin{array}{c}0.025^{* * *} \\
(3.67)\end{array}$ & $\begin{array}{c}0.016^{* *} \\
(1.99)\end{array}$ \\
\hline Individual $x$ Month FE & Yes & Yes & Yes & Yes & Yes \\
\hline Observations & 22385 & 29801 & 32550 & 31804 & 29037 \\
\hline$R^{2}$ & 0.546 & 0.584 & 0.543 & 0.556 & 0.557 \\
\hline
\end{tabular}

Panel B: After-hours

\begin{tabular}{|c|c|c|c|c|c|}
\hline & $\begin{array}{c}\text { Risky Asset } \\
\text { (1) }\end{array}$ & $\begin{array}{c}\text { Volatility } \\
\text { (2) }\end{array}$ & $\begin{array}{c}\text { Skewness } \\
\text { (3) }\end{array}$ & $\begin{array}{c}\text { Lottery Type } \\
\text { Asset } \\
(4)\end{array}$ & $\begin{array}{c}\text { Top } 10 \text { Pctl } \\
\text { Performers } \\
\quad(5)\end{array}$ \\
\hline Smartphone & $\begin{array}{c}0.025^{* * *} \\
(3.16)\end{array}$ & $\begin{array}{c}4.237^{* * *} \\
(6.00)\end{array}$ & $\begin{array}{c}8.750^{* * *} \\
(4.10)\end{array}$ & $\begin{array}{c}0.037^{* *} \\
(2.51)\end{array}$ & $\begin{array}{c}0.044^{* *} \\
(2.30)\end{array}$ \\
\hline Individual $\times$ Month FE & Yes & Yes & Yes & Yes & Yes \\
\hline $\begin{array}{l}\text { Observations } \\
R^{2}\end{array}$ & $\begin{array}{l}7401 \\
0.528\end{array}$ & $\begin{array}{l}9698 \\
0.612\end{array}$ & $\begin{array}{l}11662 \\
0.546\end{array}$ & $\begin{array}{l}10337 \\
0.575\end{array}$ & $\begin{array}{l}9414 \\
0.561\end{array}$ \\
\hline
\end{tabular}

Panel C: Morning Hour

Risky Asset Volatility Skewness Lottery Type Top 10 Pctl Asset

\begin{tabular}{lccccc}
\hline Smartphone & 0.008 & $3.124^{* * *}$ & $7.021^{* * *}$ & 0.033 & $0.019^{* * *}$ \\
& $(1.37)$ & $(6.29)$ & $(3.80)$ & $(1.62)$ & $(3.61)$ \\
Individual x Month FE & Yes & Yes & Yes & Yes & Yes \\
\hline Observations & 1370 & 2658 & 3240 & 2758 & 2602 \\
$R^{2}$ & 0.510 & 0.622 & 0.582 & 0.557 & 0.580 \\
\hline
\end{tabular}




\section{Table 11:}

Choice of Asset Classes

This table reports estimates of the regressions that examine the effect of the use of smartphones on risk taking and trend chasing within the same asset class. Assets can belong to six different asset classes namely stocks, bonds, funds, warrants, certificates and option bonds that could be converted to stocks. The outcome variables include probability of purchasing a risky assets, volatility of purchased assets, skewness of purchased assets and probability of purchasing lottery type assets. Each observation corresponds to individual $x$ month $x$ trading device level where trading device has been categorized into two groups - smartphone and all other devices. All outcome variables are aggregated from the trade-level data to the observation-level as average values and different columns include different fixed effects as indicated. Standard errors are double-clustered at individual and month level, and t-statistics are reported in parentheses. ${ }^{*},{ }^{* *}$ and ${ }^{* * *}$ represent significance at $10 \%, 5 \%$ and $1 \%$ level, respectively.

\begin{tabular}{lccccc}
\hline & Risky Asset & Volatility & Skewness & $\begin{array}{c}\text { Lottery Type } \\
\text { Asset }\end{array}$ & $\begin{array}{c}\text { Top 10 Pctl } \\
\text { Performers } \\
\end{array}$ \\
& $(1)$ & $(2)$ & $(3)$ & $(4)$ & $(5)$ \\
\hline Smartphone & 0.004 & $2.536^{* * *}$ & $3.146^{* * *}$ & $0.024^{* * *}$ & $0.027^{* * *}$ \\
& $(1.46)$ & $(13.80)$ & $(3.96)$ & $(6.01)$ & $(5.90)$ \\
Individual x Month FE & Yes & Yes & Yes & Yes & Yes \\
Asset Class x Year FE & Yes & Yes & Yes & Yes & Yes \\
\hline Observations & 636922 & 1304450 & 1304252 & 1344679 & 1289764 \\
$R^{2}$ & 0.652 & 0.722 & 0.579 & 0.555 & 0.576 \\
\hline
\end{tabular}




\section{Table 12:}

\section{Digital Nudges}

This table reports estimates of the regressions that examine the effect of the use of smartphones on risk taking as measured by volatility, skewness and probability of purchasing lottery-type stocks within different asset classes. Each observation corresponds to individual $\mathrm{x}$ month $\mathrm{x}$ trading device level where trading device has been categorized into two groups - smartphone and all other devices. All outcome variables are aggregated from the trade-level data to the observation-level as average values and different columns include different fixed effects as indicated. Standard errors are double-clustered at individual and month level, and $\mathrm{t}$-statistics are reported in parentheses. ${ }^{*}, * *$ and ${ }^{* * *}$ represent significance at $10 \%, 5 \%$ and $1 \%$ level, respectively.

Panel A: Individual Stocks

\begin{tabular}{|c|c|c|c|c|}
\hline & $\begin{array}{c}\text { Volatility } \\
\text { (1) }\end{array}$ & $\begin{array}{c}\text { Skewness } \\
\text { (2) }\end{array}$ & $\begin{array}{c}\text { Lottery Type } \\
\text { Asset } \\
\text { (3) }\end{array}$ & $\begin{array}{c}\text { Top } 10 \text { Pctl } \\
\text { Performers } \\
\quad(4)\end{array}$ \\
\hline Smartphone & $\begin{array}{c}1.531^{* * *} \\
(5.67)\end{array}$ & $\begin{array}{c}3.085^{* * * *} \\
(3.32)\end{array}$ & $\begin{array}{l}0.009^{*} \\
(1.66)\end{array}$ & $\begin{array}{c}0.017^{* *} \\
(2.38)\end{array}$ \\
\hline Individual $x$ Month FE & Yes & Yes & Yes & Yes \\
\hline $\begin{array}{l}\text { Observations } \\
R^{2}\end{array}$ & $\begin{array}{c}140755 \\
0.520\end{array}$ & $\begin{array}{c}140737 \\
0.514\end{array}$ & $\begin{array}{c}142296 \\
0.519\end{array}$ & $\begin{array}{c}138810 \\
0.522\end{array}$ \\
\hline
\end{tabular}

Panel B: Mutual Funds

\begin{tabular}{|c|c|c|c|c|}
\hline & $\begin{array}{c}\text { Volatility } \\
\text { (1) }\end{array}$ & $\begin{array}{c}\text { Skewness } \\
\text { (2) }\end{array}$ & $\begin{array}{c}\text { Lottery Type } \\
\text { Asset } \\
\text { (3) }\end{array}$ & $\begin{array}{c}\text { Top } 10 \text { Pctl } \\
\text { Performers } \\
\quad(4)\end{array}$ \\
\hline Smartphone & $\begin{array}{l}3.810^{* * *} \\
(10.80)\end{array}$ & $\begin{array}{c}9.477^{\text {*** }} \\
(3.37)\end{array}$ & $\begin{array}{c}0.079^{* * *} \\
(7.36)\end{array}$ & $\begin{array}{c}0.056^{* * *} \\
(5.81)\end{array}$ \\
\hline Individual $x$ Month FE & Yes & Yes & Yes & Yes \\
\hline $\begin{array}{l}\text { Observations } \\
R^{2}\end{array}$ & $\begin{array}{l}456742 \\
0.499\end{array}$ & $\begin{array}{c}456720 \\
0.494\end{array}$ & $\begin{array}{c}457271 \\
0.503\end{array}$ & $\begin{array}{c}454062 \\
0.501\end{array}$ \\
\hline
\end{tabular}


Panel C: Certificates, Options \& Warrants

\begin{tabular}{lcccc}
\hline & Volatility & Skewness & $\begin{array}{c}\text { Lottery Type } \\
\text { Asset } \\
(3)\end{array}$ & $\begin{array}{c}\text { Top 10 Pctl } \\
\text { Performers } \\
(4)\end{array}$ \\
\hline smartphone & $(1)$ & $(2)$ & 0.022 & 0.031 \\
& $4.201^{* * *}$ & 7.056 & $(0.98)$ & $(0.91)$ \\
Individual x Month FE & Yes & Yes & Yes & Yes \\
\hline Observations & 2525 & 2521 & 4274 & 2475 \\
$R^{2}$ & 0.562 & 0.551 & 0.556 & 0.566 \\
\hline
\end{tabular}




\section{Table 13:}

Device Screen Size

This table reports estimates of the regressions that examine the effect of the use of smartphones and iPad on risk taking. The outcome variables include probability of purchasing a risky assets, volatility of purchased assets, skewness of purchased assets and probability of purchasing lottery type assets. Each observation corresponds to individual $\mathrm{x}$ month $\mathrm{x}$ trading device level where trading device has been categorized into two groups - smartphone and all other devices. All outcome variables are aggregated from the trade-level data to the observation-level as average values and different columns include different fixed effects as indicated. Standard errors are double-clustered at individual and month level, and t-statistics are reported in parentheses. ${ }^{*},{ }^{* *}$ and ${ }^{* * *}$ represent significance at $10 \%, 5 \%$ and $1 \%$ level, respectively.

Panel A: Within-Individual Variation

\begin{tabular}{|c|c|c|c|c|c|}
\hline & $\begin{array}{c}\text { Risky Asset } \\
\text { (1) }\end{array}$ & $\begin{array}{l}\text { Volatility } \\
\text { (2) }\end{array}$ & $\begin{array}{c}\text { Skewness } \\
\text { (3) }\end{array}$ & $\begin{array}{c}\text { Lottery Type } \\
\text { Asset } \\
(4)\end{array}$ & $\begin{array}{c}\text { Top } 10 \text { Pctl } \\
\text { Performers } \\
\text { (5) }\end{array}$ \\
\hline Smartphone & $\begin{array}{c}0.018^{* * *} \\
(4.66)\end{array}$ & $\begin{array}{c}2.819^{* * *} \\
(6.86)\end{array}$ & $\begin{array}{c}7.792^{* * *} \\
(4.86)\end{array}$ & $\begin{array}{c}0.026^{* * *} \\
(3.34)\end{array}$ & $\begin{array}{c}0.035^{* * *} \\
(3.15)\end{array}$ \\
\hline iPad & $\begin{array}{c}0.015^{* *} \\
(2.45)\end{array}$ & $\begin{array}{c}2.999^{* * *} \\
(4.35)\end{array}$ & $\begin{array}{c}15.502^{* * *} \\
(5.30)\end{array}$ & $\begin{array}{c}0.055^{* * *} \\
(4.70)\end{array}$ & $\begin{array}{c}0.048^{* * *} \\
(2.75)\end{array}$ \\
\hline Individual FE & Yes & Yes & Yes & Yes & Yes \\
\hline Year FE & Yes & Yes & Yes & Yes & Yes \\
\hline Observations & 18295 & 23241 & 23237 & 24193 & 23007 \\
\hline$R^{2}$ & 0.519 & 0.460 & 0.225 & 0.248 & 0.284 \\
\hline
\end{tabular}

Panel B: Within- \& Across- Individual Variation

\begin{tabular}{|c|c|c|c|c|c|}
\hline & $\begin{array}{c}\text { Risky Asset } \\
\text { (1) }\end{array}$ & $\begin{array}{c}\text { Volatility } \\
\text { (2) }\end{array}$ & $\begin{array}{c}\text { Skewness } \\
\text { (3) }\end{array}$ & $\begin{array}{c}\text { Lottery Type } \\
\text { Asset } \\
\text { (4) }\end{array}$ & $\begin{array}{c}\text { Top } 10 \text { Pctl } \\
\text { Performers } \\
\quad(5)\end{array}$ \\
\hline Smartphone & $\begin{array}{c}0.031^{* * *} \\
(6.89)\end{array}$ & $\begin{array}{c}4.842^{* * *} \\
(6.03)\end{array}$ & $\begin{array}{c}11.435^{* * *} \\
(4.52)\end{array}$ & $\begin{array}{c}0.039^{* * *} \\
(3.55)\end{array}$ & $\begin{array}{c}0.071^{* * *} \\
(3.76)\end{array}$ \\
\hline iPad & $\begin{array}{l}0.017^{* *} \\
(2.17)\end{array}$ & $\begin{array}{c}3.192^{* * * *} \\
(2.91)\end{array}$ & $\begin{array}{c}16.554^{* * *} \\
(4.91)\end{array}$ & $\begin{array}{c}0.051^{* * *} \\
(3.36)\end{array}$ & $\begin{array}{c}0.056^{* * * *} \\
(2.90)\end{array}$ \\
\hline Year FE & Yes & Yes & Yes & Yes & Yes \\
\hline $\begin{array}{l}\text { Observations } \\
R^{2}\end{array}$ & $\begin{array}{l}18379 \\
0.005\end{array}$ & $\begin{array}{r}23311 \\
0.088\end{array}$ & $\begin{array}{r}23307 \\
0.031\end{array}$ & $\begin{array}{r}24255 \\
0.011\end{array}$ & $\begin{array}{l}23078 \\
0.009\end{array}$ \\
\hline
\end{tabular}




\section{Smart(Phone) Investing?}

Appendix for Online Publication 


\section{Figure A1:}

Trading Hour Density

This figure plots density for hour of the day that trade occurs by different asset classes.

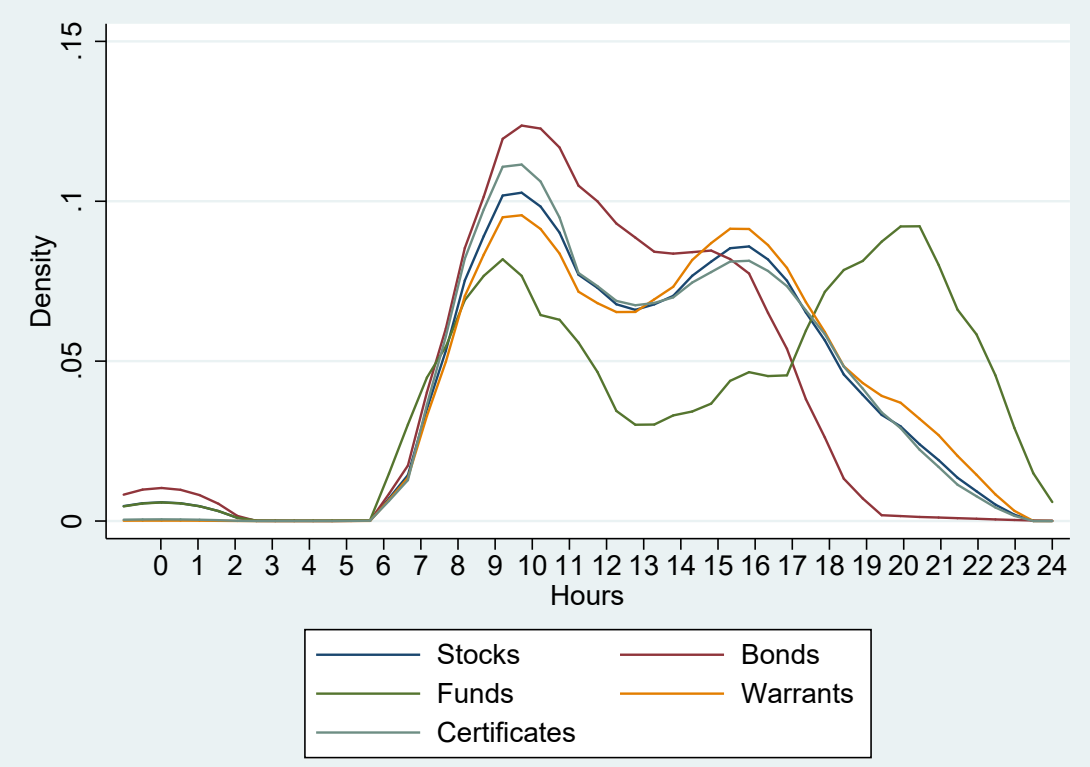




\section{Table A1:}

Riskiness of Assets Purchased

This table reports estimates of the regressions that examine the effect of the use of smartphones on risk taking as measured by measured by the risk categories assigned by the banks (which classify all assets into five risk categories). Each observation corresponds to individual $\mathrm{x}$ month $\mathrm{x}$ trading device level where trading device has been categorized into two groups - smartphone and all other devices. All outcome variables are aggregated from the trade-level data to the observation-level as average values and different columns include different fixed effects as indicated. Standard errors are double-clustered at individual and month level, and t-statistics are reported in parentheses. ${ }^{*}, * *$ and ${ }^{* * *}$ represent significance at $10 \%, 5 \%$ and $1 \%$ level, respectively.

\begin{tabular}{lcccc}
\hline & \multicolumn{4}{c}{ Risk Categories of Assets Purchased } \\
& $(1)$ & $(2)$ & $(3)$ & $(4)$ \\
\hline Smartphone & $0.248^{* * *}$ & $0.049^{* * *}$ & $0.098^{* * *}$ & $0.163^{* * *}$ \\
& $(16.02)$ & $(7.59)$ & $(11.89)$ & $(14.32)$ \\
Individual FE & No & Yes & No & No \\
Year FE & No & Yes & No & No \\
Individual x Year FE & No & No & Yes & No \\
Individual x Month FE & No & No & No & Yes \\
\hline Observations & 2551671 & 2535135 & 2500436 & 1610230 \\
$R^{2}$ & 0.002 & 0.567 & 0.548 & 0.501 \\
\hline
\end{tabular}


Table A2:

Probability of Purchasing Warrants/Certificates

This table reports estimates of the regressions that examine the effect of the use of smartphones on risk taking as measured by the probability of purchasing warrants/certificates. The outcome variable for Panel A (B) includes the probability of purchasing warrants (certificates). Each observation corresponds to individual $\mathrm{x}$ month $\mathrm{x}$ trading device level where trading device has been categorized into two groups - smartphone and all other devices. All outcome variables are aggregated from the trade-level data to the observationlevel as average values and different columns include different fixed effects as indicated. Standard errors are double-clustered at individual and month level, and $t$-statistics are reported in parentheses. ${ }^{*},{ }^{* *}$ and ${ }^{* * *}$ represent significance at $10 \%, 5 \%$ and $1 \%$ level, respectively.

Panel A

\begin{tabular}{lcccc}
\hline & \multicolumn{4}{c}{ Probability of Purchasing a Warrant } \\
& $(1)$ & $(2)$ & $(3)$ & $(4)$ \\
\hline Smartphone & $0.16^{* * *}$ & $0.03^{* * *}$ & $0.07^{* * *}$ & $0.12^{* * *}$ \\
& $(5.01)$ & $(3.98)$ & $(9.35)$ & $(8.13)$ \\
Individual FE & No & Yes & No & No \\
Year FE & No & Yes & No & No \\
Individual x Year FE & No & No & Yes & No \\
Individual x Month FE & No & No & No & Yes \\
\hline Observations & 2589595 & 2573148 & 2539461 & 1657381 \\
$R^{2}$ & 0.007 & 0.689 & 0.597 & 0.493 \\
\hline
\end{tabular}

Panel B

\begin{tabular}{lcccc}
\hline & \multicolumn{4}{c}{ Probability of Purchasing a Certificate } \\
& $(1)$ & $(2)$ & $(3)$ & $(4)$ \\
\hline Smartphone & $0.02^{*}$ & $0.01^{* *}$ & $0.01^{* *}$ & $0.01^{* *}$ \\
& $(2.04)$ & $(3.25)$ & $(2.57)$ & $(2.19)$ \\
Individual FE & No & Yes & No & No \\
Year FE & No & Yes & No & No \\
Individual x Year FE & No & No & Yes & No \\
Individual x Month FE & No & No & No & Yes \\
\hline Observations & 2589595 & 2573148 & 2539461 & 1657381 \\
$R^{2}$ & 0.000 & 0.468 & 0.502 & 0.505 \\
\hline
\end{tabular}




\section{Table A3:}

Choice of Trading Hours \& Asset Classes

This table reports estimates of the regressions that examine the effect of the use of smartphones on risk taking and trend chasing within the same trading hour and asset class. Assets can belong to six different asset classes namely stocks, bonds, funds, warrants, certificates and option bonds that could be converted to stocks. The outcome variables include probability of purchasing a risky assets, volatility of purchased assets, skewness of purchased assets and probability of purchasing lottery type assets. Each observation corresponds to individual $\mathrm{x}$ month $\mathrm{x}$ trading device level where trading device has been categorized into two groups - smartphone and all other devices. All outcome variables are aggregated from the trade-level data to the observation-level as average values and different columns include different fixed effects as indicated. Standard errors are doubleclustered at individual and month level, and $\mathrm{t}$-statistics are reported in parentheses. ${ }^{*}, * *$ and ${ }^{* * *}$ represent significance at $10 \%, 5 \%$ and $1 \%$ level, respectively.

\begin{tabular}{|c|c|c|c|c|c|}
\hline & $\begin{array}{c}\text { Risky Asset } \\
\text { (1) }\end{array}$ & $\begin{array}{c}\text { Volatility } \\
\text { (2) }\end{array}$ & $\begin{array}{c}\text { Skewness } \\
\text { (3) }\end{array}$ & $\begin{array}{c}\text { Lottery Type } \\
\text { Asset } \\
\text { (4) }\end{array}$ & $\begin{array}{l}\text { Top } 10 \text { Pctl } \\
\text { Performers } \\
\quad(5)\end{array}$ \\
\hline Smartphone & $\begin{array}{l}0.001 \\
(0.23)\end{array}$ & $\begin{array}{l}1.344^{* * *} \\
(4.80)\end{array}$ & $\begin{array}{c}3.522^{* * * *} \\
(2.98)\end{array}$ & $\begin{array}{c}0.017^{* * *} \\
(2.98)\end{array}$ & $\begin{array}{l}0.014^{*} \\
(1.85)\end{array}$ \\
\hline Individual $x$ Month FE & Yes & Yes & Yes & Yes & Yes \\
\hline $\begin{array}{l}\text { Asset Class } \mathrm{x} \\
\text { Trading Hour x Year FE }\end{array}$ & Yes & Yes & Yes & Yes & Yes \\
\hline $\begin{array}{l}\text { Observations } \\
R^{2}\end{array}$ & $\begin{array}{l}33642 \\
0.805\end{array}$ & $\begin{array}{l}48671 \\
0.708\end{array}$ & $\begin{array}{l}48657 \\
0.609\end{array}$ & $\begin{array}{l}51235 \\
0.600\end{array}$ & $\begin{array}{l}47665 \\
0.614\end{array}$ \\
\hline
\end{tabular}

